Volume 26, Number 1, Spring 1997

ISSN 0710 - 4340

Considerations in the Construction of

Technology - Based Virtual Learning

Communities

Eugene Kowch

Richard Schwier

Towards Optimising the Organisational and

Educational Effectiveness of

Videoconferencing for Vocational Education

Stephen Towers

Roy Lundin

Patrick Macguire

Information Clues in Topical Web Searches:

Is the Web Message Getting Through

Mary Ann Epp

An AMTEC Publication 


\section{Editorial Board}

Farough Abed

Central Connecticut State

University

Terry Anderson

Unrversity of Alberta

Jon Baggaley

Athabasca University

Robert M Branch

University of Georgia

Katy Campbell

University of Alberta

Bruce Clark

University of Calgary

Dan Coldeway

Athabasca University

Denis Daigneault

Dagneault Multimedia

Thomas M Duffy

Indiana University

Rodney S. Earle

Brigham Young University

D J Engel

Unrversty of Alberta

George L Geis

OISE

Edward S. Halpern

$A T \& T$ Bell Laboratories

Michael Hannafin

University of Georgia

Denis Hlynka

Unrversrty of Manitoba
W. J. Hunter

University of Calgary

Robert Jones

Sheridan College of Applied

Arts and Technology

Richard Kenny

University of Ottawa

Lorne Koroluk

University of British Columbia

Richard F. Lewis

University of Windsor

William Milhelm

Penn State Great Valley

Earl R. Misanchuk

University of Saskatchewan

Norma Nocente

University of Alberta

Ronald Owston

York University

Lauran Sandals

University of Calgary

Richard F. Schmid

Concordia University

Richard A. Schwier

University of Saskatchewan

Donna Sharon

Consultant, London, ON

Steven Shaw

Concordia University

Clayton R. Wright

Grant MacEwan Community College
Amtec Board of Directors

\section{President}

Katy Campbell

University of Alberta

Past President

Richard A Schwrer

Unrversrty of Saskatchewan

President Elect

Genevieve Gallant

Memorial University of

Newfoundland

\section{Secretary/Treasurer}

Mary Anne Epp

\section{Director (Awards)}

Maureen Baron

Director (Membership)

Brian Smalridge

Champlain College 
Canadian Journal of

\section{Educational}

Communication

Volume 26, Number 1

Spring, 1997

\section{Editor}

David A. Mappin

\section{Guest Editors}

Katy Campbell

Richard Schwier

\section{Mediaware Review Editor}

Len F. Proctor

\section{Book Review Editor}

Diane P. Janes

\section{Translation}

Dorine Chalifoux

\section{Production Manager \\ Pat Mannion \\ Patrician Desktop Publishing}

The Canadian Journal of Educational Commumcation i fpublished by the Association for Media and technology in Education in Canada: 3- 1750 'I he Queensway, Suite 1318. Etobicoke,

Ontario M9C 5115. Attention; Ms. Mary Anne Epp, Secretary/ I rcaaurer. Notification of address change should be sent to the above. All articles are copyright by AMTEC and may be reproduced for non-profit use without permission provided credit is given to CJEC. Back Issues of CJEC are $\$ 16.05$ Canadian and may be obtained by contacting the Editor. CJEC is indexed in the Canadian Education Index and ERIC

This journal is published with the assistance of a grant from the Social Sciences and Humanities Research Council of Canada.

\section{Articles}

\section{Special Conference Issue}

Considerations in the Construction

of Technology - Based Virtual

Learning Communities . .

Eugene Kowch

Richard Schwier

Towards Optimising the

Organisational and Educational

Effectiveness of Videoconferencing

for Vocational Education . 13

Stephen Towers

Roy Lundin

Patrick Maguire

Information Clues in Topical Web

Searches: Is the Web Message

Getting Through......................... 43

Mary Ann Epp

Book Reviews. . . . . . . . 53

Microware Review .................. 57

All Correspondence should be addressed to

\section{David Mappin}

Division of Technology in Education

3- 102 Education North

University of Alberta

Edmonton, Alberta T6G 2G5

E-Mail: David Mappin@Ualberta.ca

CJEC is typeset in PageMaker 6 .

Printed by: Quebecor Jasper Printing Inc.

Edmonton. AB. 
$1997-98$

Subscription/

Membership Form

Name:

Address:

City

Prov/Postal Code

Phone(w)

Fax

Title:

Phone (h)

Netmail
AMTEC c/o Brian Smalridge

3-1750 The Queensway, Suite 1818

Etobiocoke, Ontario, Canada M9C 5H5

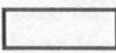

I am willing to have pertinent information from the above included in the next Members Handbook

ALL RENEWASL COME DUE ON EITHER JANUARY IST OR JUNE IST

If this is a renewal then please indicate your Membership Number

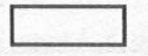

Student of Educational Technology (includes GST) $\$ 53.50$

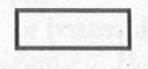

Retiree (includes GST)

Individual (Includes GST)

Commercial (includes GST)

CJEC Subscription Only - Canada (includes GST) $\$ 80.25$

CJEC Subscription Only - U.S.A. US $\$ 75.00$

CJEC Subsription - Outside North America US $\$ 95.00$

*Students must have this form signed by your Department Head GST \# 122939853 


\title{
Considerations in the Construction of Technology - Based Virtual Learning Communities
}

\author{
Eugene Kowch \\ Richard Schwier
}

\begin{abstract}
This article discusses the construct of learning 'community' for educators and proceeds to examine fundamental issues around the theory and practice of constructing learning communities using communication technologies (virtual learning communities). This concept of community asks the reader to ponder some possible shapes virtual learning communities could take in the future, and the contribution that communication technologies $\mathrm{c}$ a n make to designing powerful learning environments.
\end{abstract}

Résumé: Cet article débute avec une discussion de la notion d'une «communauté» d'apprentissage pour les enseignants, pour ensuite passer a l'examen de questions fondamentales entourant la théorie et la pratique de la construction de communautés d'apprentissage reposant sur la technologie des commumcations (des communautés virtuelles technologtsées) Ce concept dc communauté pousse le lecteur à réfléchir aux formes possibles que pourraient adopter ces communautés virtuelles technologtsées a l'avenu. ainsi qu'a la contribution que la technologie des communications pourrait apporter à la conception de milieux d'apprentissage fertiles.

\section{A Definition of Learning Community}

Communities are collections of individuals who are bound together by shared ideologies and will, so a learning community emerges when people are drawn together to learn. Although learning communities emphasize outcomes in education, their power resides in their ability to take advantage of, and in some cases, invent a process for learning. In Nichomachean Ethics, Aristotle explains that community is not SO much about unity as it is about harmony (Aristotle cited in Porter, 1997, p. 135). Harmony can exist within social, religious, political and moral frameworks, and as a result, communities can emphasize one or more of these dimensions.

This definition of a learning community is partly woven from Kantian principles emphasizing that people operate from a rational, autonomous will, both as individuals and within groups. Individuals within a learning community (including students, teachers and administrators) have a will to do what is "right" and "good" in accordance with agreed values and ethical principles. For example, if a shared principle is to respect individuals, members of learning communities might attack ideas vigorously, but avoid personal attacks. These relationships exemplify moral reasoning, not instrumental reason. Kantian principles suggest that a learning community emerges when the "I" considers the "We" (Honderich, 1995, p. 439) and this is dependent on open discourse among participants and underlying principles (e.g.- freedom to take risks, unconditional acceptance, shared 
responsibility, everybody feeling obligated to do the right thing). To support discourse within the community, this article considers some ideas outside conventional community research including "the power of technology to reconfigure social space and social interaction" (Stone, 1992, p. 86). Interaction is key, and interaction can be facilitated by many modes of face to face and mediated (electronic) communication.

Learning communities depend on relationships, and relationships can be built by using many non-traditional (electronic) interactions, not just through face-toface interactions. For example, we have all experienced developing a telephone relationship with someone in another office, and only attaching a face to the person much later. The relationship probably developed quite naturally over time, based on common concerns or issues. Similarly, learning communities can support the development of virtual relationships if the learning environment encourages individuals to interact naturally. Virtual learning communities are learning communities where learners are separated physically and must rely entirely on communication technology to mediate relationships. "The problem for community architects is to create a system in which people can enter into relations that are determined by problems or shared ambitions rather than by rules or structure" (Heckscher, 1994, p. 24). Community requires a highly interactive, loosely structured organization with tightly knit relations based on personal persuasion and interdependence:

The networking of individuals from technically [and artistically] separate areas [happens] to the extent that clear external boundaries of the organization [community] become faintly magical (Nohria and Berkely, 1994, p. 1 15).

This definition maintains that a learning community must be open -allowing learners and educators to engage in any learning opportunity with whomever they choose, from among many sources and cultures. This permits everyone to develop relationships with other learners and educators outside the traditional boundaries of the school. With technology, virtual learning communities can be built using both synchronous and asynchronous communications media while the group learns from the construction process itself.

\section{Designing Learning Communities}

Before we build virtual learning communities, we need to consider the place of a learning community within a theoretical framework that considers the full power of a technologically integrated world. Sergovanni (1996) offers a foundation for building these learning structures by proposing four key considerations.

First, the community should be aesthetically pleasing. Beyond the 'physical' characteristics, forms of communication such as language should be appealing: participants should be able to select a form "that they find most appealing most useful" (Sergiovanni, 1996, p. 32). 
Second, designers should consider moral connections within this community where the "I" thinks about the "We". Moral reasoning requires us to teach our learners and ourselves techniques for examining personal values and constructing new values.

The third consideration is technology. We must consider robust, innovative approaches to technology-enhanced communication that fit the learning community. Utilitarian means-ends theories emphasize linear, hierarchical lines of communication, and they only work where linear relationships exist. However, linear relationships and linear communications seldom exist in reality; the 'grapevine' and communication media mock the idea of hierarchical communication. Designers need to consider the ubiquitous, multidirectional nature of communication when designing virtual learning communities.

Finally, Sergiovanni considers constructivist principles of learning to be the fourth pillar supporting the learning community. Most importantly we should incorporate an understanding of what teachers, parents and students wish to accomplish: "At the root of it [theory] is the simple idea that children and adults construct their own understanding of the world in which they live" (Sergiovanni, 1996 , p. 38). When we open up dense, integrated, interactive channels of communication for parents, students, teachers and administrators we open our community to deeper opportunities for learning.

By considering these four major issues we can begin to develop a technologically supported community that is inclusive, open and self-managing. Etzioni reminds us that a collective rationality "can emerge from integrating all of our values, emotions, beliefs and social bonds and that our definition must accommodate this level of integration (Etzioni, 1992, p. 63). Our practice in community building should consider the emergence of such collective rationalities when learners make more decisions about what to learn.

\section{Building Virtual Learning Communities}

How does one begin a virtual learning community construction project? A necessary step is to explore the structure of learning communities and consider how technology will support the relationships within them.

First, it is important to realize that building community is not an organizational engineering problem - the problem is one of establishing a moral community. If harmony is one of our goals, the process must integrate moral reasoning with technological literacy. Second, research suggests that communities "are organized around relationships and ideas"(Sergiovanni, 1996, p. 48). Builders need to know the nature of the various relationships that exert influence on the group to provide communication venues for participants.

Virtual learning communities need to provide social structures that bond people together in a "oneness" so that a feeling of belonging is shared. A mixture of interpersonal contact (either in 'cyberspace' or in person) is essential to building trust in a community of learners. Sharing and learning within a discourse based on 
morals, values and principle conditions can create frequent dialogue possible only when everyone defines these principles with a common moral voice.

Learning communities can be built to encourage people to work together - so that curriculum and instruction can be distributed as part of community discourse without the barriers of the metaphorical 'closed classroom door' and heavily bureaucratic administrative hierarchies. Some key characteristics of this conception of a learning community are outlined in Figure 1.

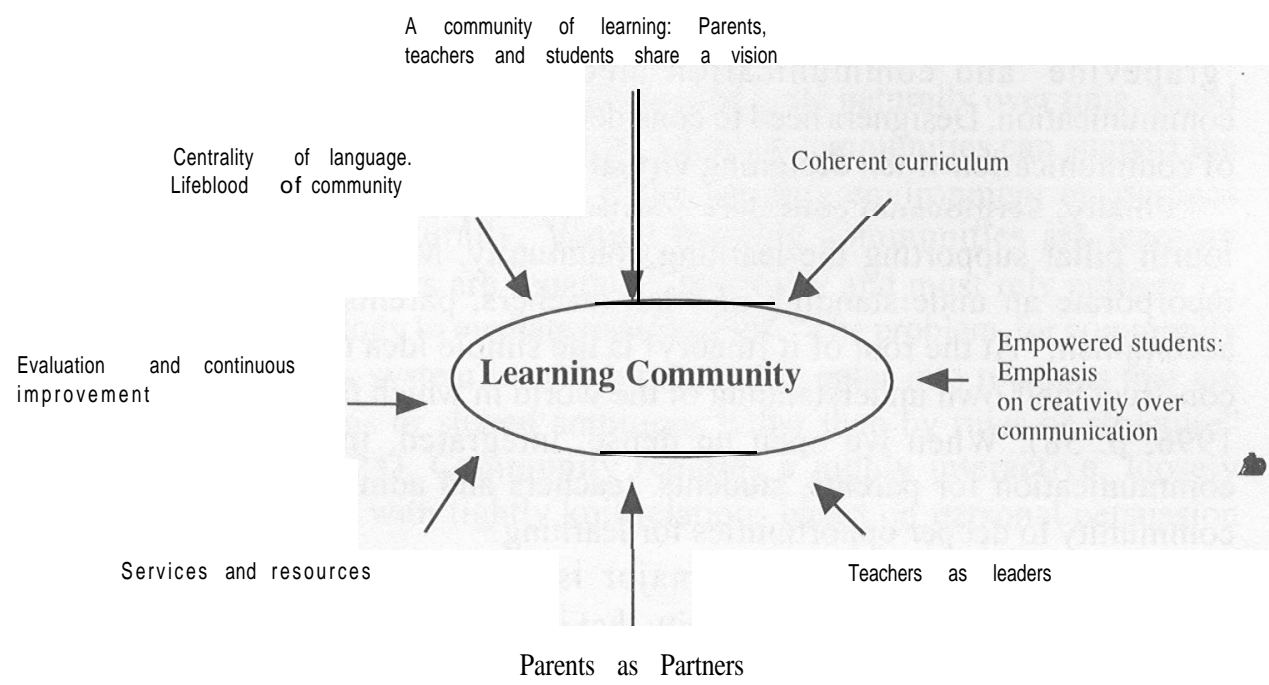

Figure 1: Key characteristics of a learning community

\section{Types of Virtual Learning Communities}

Virtual learning communities are learning communities based not on actual geography, but on shared purpose emerging from the learning process. Through technology, learners can be drawn together from almost anywhere, and they can construct their own formal or informal groups. As such, virtual learning communities are separated by space, but not time, as communication can be facilitated by technology in real time, partially overcoming geographical inhibitions. Borrowing from the work of Bellah (1985), there are at least four types of virtual learning communities, with concomitant purposes they serve.

\section{Virtual Learning Communities of Relationship}

A community built on relationships promotes special kinds of connections among people, less hierarchical interconnections that result in a peculiar harmony similar to that found in families or collections of people (Senge, 1994, p. 217). These connections might be based on a shared concern; issue or learning problem, but in each instance, the emphasis is on the relationships built among participants. 
Issues of commitment, trust and values are inherent in any relationships that emerge in and around the community.

Many robust examples of this type of community exist, but one of the most powerful has been the emergence of support groups for women on the World Wide Web. Women have developed web sites for dealing with abuse, single parenting and harassment in the workplace, for example, and have used them as places for sharing experiences, discussing problems and pondering advice.

\section{Virtual Learning Communities of Place}

Individuals in communities of place enjoy a common habitat or locale. Sharing place with others can offer a sense of security, commonality, and heritage. The place need not be physical, however, and in virtual communities, places are by definition not physical. People from several countries can gather in one virtual place on the Internet, for example, as easily as people can gather for a meeting in a school building (perhaps easier). Nevertheless, the location can be as real as the imagination and technology allow. The World Wide Web houses thousands of virtual store fronts, for example, each of which exists metaphorically as a place.

An example of a virtual community of place is "Marathon," a computer-based network game, in which participants meet in a virtual location and exploit it in a competition. The virtual world is housed centrally, and individuals enter it from any location on the network. They can develop common strategies, team with or against other players in real time, and the actions of any player influences the game dynamically. Players can also construct their own environment, and invite other participants into that "place." Marathon is a game with few, if any, learning outcomes attached, but it illustrates some of the characteristics of virtual learning communities of place. Virtual places could also be designed around shared learning adventures, say, the physiology of the brain, or the House of Commons, and participants could interact dynamically in the places.

\section{Virtual Learning Communities of Mind}

Communities of mind reinforce people's commitment to other people, to common goals, shared values and shared conceptions of being and doing. This can be as trivial as a shared interest in making wine, or as profound as a shared search for truth in scripture. The two most distinguishable features of a community of mind are sharing and ideas, however they may be expressed interpersonally or technologically.

Examples of learning communities of mind are often found in academic settings, where researchers come together to grapple with a shared research issue or problem. But this type of community, as with other types, is not always positive or prosocial. Many dark examples of this type of community can be found on the Internet in web sites and chat groups that focus on hate. The World Wide Web is replete 
with hate mongers who promote intolerance toward all manner of religious, ethnic and political groups.

\section{Virtual Learning Communities of Memory}

A virtual learning community of memory is based on a shared past or a common sense of history. This type of community promotes connection between people who might otherwise be alone, and also provides a focal point for interpreting and understanding commonly experienced events.

A very powerful example of this is found with the Holocaust survivors' network on the Internet. Survivors and descendants of survivors can engage in discourse with others whose lives have been touched by this tragedy. Through virtual discussion, they have an opportunity to understand the causes and effects of the Holocaust, and provide support to other people in the community who share the memory. By participating within a community of memory, we are effectively managing our temporal learning environment.

\section{Characteristics of Virtual Learning Communities}

In order to understand the nature of the contribution technology can make to building virtual learning communities, it is necessary to distinguish between traditional conceptions of technology and the kinds of contributions technology can make to building learning communities. Traditionally, when people think of technology, they think of conventional instructional media-television, film, and computers - as means of delivering or presenting material (Ely, 1995, p. 55). Certainly traditional media have made many contributions to education. schools, communities and ultimately, learning. Most school divisions have developed extensive libraries of resources, and everything from a set of maps to a complete trigonometry course on videodisc have been used by teachers to support instruction.

But the reader may have noticed that this paper refers only tangentially to the hardware and software commonly labelled as "technology" by educators. The type oftechnology we are talking about in this paper emphasizes technology as a medium for expression and communication. Used as a communication tool, technology offers opportunities for extending learning beyond the boundaries of classroom, province and country, and this in turn promotes the development of a rich tapestry of formal and informal learning communities. A virtual learning community employs technology to communicate; therefore, it can, and does, happen anywhere, and it can be constructed anywhere. anytime. The idea of construction is central to the notion of virtual communities. as what the community creates becomes the collective product and process of its individual members. In order to satisfy our requirements for a virtual learning community, a technology must permit each of the following conditions:

\section{Negotiation}

While virtual communities are often built around central themes, ideas or purposes, the organizing principles are not externally imposed. Participants construct purposes. 
intentions and the protocol for interaction. Systems within the community-allow open and unrestricted access based on individual interests, and dialogue "across the boundaries of formal power and status" (Heckscher, 1994, p. 142)

\section{Intimacy}

Participants can achieve personally gratifying levels of intimacy with other participants, and can select the level of intimacy appropriate for any negotiated relationship with another participant. Anonymity is possible, but as the sense of community develops, it is unlikely that a participant would choose to remain anonymous.

\section{Commitment}

The quality of participation depends on individual and shared commitment or relevance of the substance of the community. Commitment depends on shared values in the community and "earned respect" for particular skills and knowledge; where participation represents an ethical choice and influence among those who share goals or needs (Nohria and Berkley. 1994, p. 1 OS). The valence of the commitment need only be strong enough to maintain participation in the group, but stronger commitment generally leads to the development of stronger, more flexible communities.

\section{Engagement}

Participants interact with each other and have the capacity to conduct discourse freely and meaningfully. III order to fit our definition, engagement must have immediacy not be significantly delayed in time or space. Interaction must be effervescent. and based on influence among participants rather than power relationships.

Each of these components is necessary for meaningful communication to take place between and among individuals, and we suggest that communication, in the form of legitimate discourse. is central to the notion of building learning communities. In order to examine how these components contribute to the development of virtual learning communities, we will examine a few examples of virtual learning communities, and also look at some technologies that might be mistaken for virtual learning communities.

One of the simplest examples of a virtual learning community is a conference telephone call. Requiring only a telephone for each participant and a bridge to connect them, it allows participants a full range of negotiation, intimacy, commitment and engagement. A teleconference (n-way video and audio) accomplishes the same purposes as a conference telephone call. but also permits visual communication. Desktop video allows participants to mount inexpensive video cameras on computers and transmit slow scan video and telephone quality audio over telephone lines, and establish a connection between two computers. The image of each participant appears in a small window on the computer screen 
of the other participant. Special software can be used to establish a reflector site, which acts like a video bridge for several participants at the same time.

A chat room is another technology available forjoining several participants in a community of discourse. Simply speaking, chat rooms are locations on the Internet that gather keyboard input from two or more individuals as they type. Everyone logged into the chat room can view the posted material and respond to the comments of others. Chat rooms are usually organized around a specific topic or area of interest, and the topics are as wide-ranging as the imaginations of the participants. Participants can use their own names or pseudonyms, personally controlling whatever is a comfortable amount of intimacy. In crowded chat rooms, interaction can become quite confusing, as one participant responds out of sequence to an item presented much earlier in the on-screen discussion among several people. So it is common for individuals to pair off and agree to meet in another, private room. It all sounds quite seductive, and certainly can be, but in most cases, private rooms are used to pursue a specific conversation more intensely with another individual. Chat rooms are often moderated by an individual who monitors discussion and facilitates interaction. Participants typically monitor discourse too, and are quick to isolate an individual who contributes inappropriate or unsavoury material. In this way, protocol is constantly negotiated. Chat rooms provide a rich example of technology that facilitates negotiation, intimacy, commitment and engagement. How can they be turned into virtual learning environments? First, teachers can build chat rooms around specific topics of discussion and help moderate and participate in discussions. Classroom activities and projects can be designed to encourage students to use chat rooms to collaborate with other students in problemsolving activities. Teachers can also help students develop skills in framing arguments, conducting on-line discussions, and understanding the protocol and etiquette of communicating through this technology. In some cases, it may be necessary for educators to closely monitor the chat rooms, to help keep the focus of discussion on learning activities, and even to remove intruders who enter the room to cause mischief.

There are, of course, limitations to each of these examples. One of the most dramatic, is access. Each technology, even the most modest, requires some hardware and budget to support interaction. Some technologies introduce specific barriers. For example, access to chat rooms require keyboarding skills. Poor typing skills limit the amount and quality of the interaction, and probably test the patience of other participants

At the same time, the examples illustrate how inclusive such communities can be. Individuals with disabilities, those living in remote or rural areas, and those who have difficulty participating in groups can all be part of virtual communities.

There are several technologies which appear to support virtual learning communities, but which do not. There are many websites which offer excellent material to educators, but which do not make any of promoting negotiation or engagement. Perhaps the most prevalent, and growing example of this, can be 
found in the array of university courses now available on the web. Most provide an electronic version of a print-based correspondence course, and challenge the learner to read material and extract information. These sites can have great value, but they should not be confused with learning communities, as they do not permit discourse. Some websites pretend intimacy and engagement, but merely simulate actual conversation rather than engage in discourse with the user. For example, psychic hotlines are available which give the impression of real, intimate and engaged discussion, when in fact, the conversation is not negotiated by the participants as it is controlled by the "host."

Televised distance education programs with fax and phone callback are among the easiest educational innovations to confuse with virtual learning communities. In these programs, a teacher typically teaches a class to the camera or to a group of students in the studio. Students at remote locations can interrupt the instructor with comments, questions or faxes, but unless the instructor is highly skilled at conducting mediated discussions, there will be little actual give-and-take in the conversation. This can provide a serious source of frustration to teachers who usually depend on classroom discussion to carry a class, as the technology can serve to isolate learners from the teacher. As an aside. we suspect that this is precisely why some distance education initiatives fair because the technology promotes transmission of information rather than the construction of learning communities. It is not the fault of the teleteacher or the technology, yet it is a natural outcome of the interaction between the two.

Listserves and electronic mail are also easily mistaken for virtual learning communities. A listserv is a location for posting mail messages on a particular topic to subscribers to that listservice. It is very similar to a chat room, with one important difference: participants in the listserv are not in the location at the same time. Listserv participants drop mail into a location; chat room participants drop into a location and type messages in real time to each other. Thus, the engagement is not immediate and negotiated. Listserves and e-mail have important contributions to make to education and learning, but they are not examples of platforms that promote the development virtual learning communities. Although they may be useful for supporting learning and learning communities, they do not provide the quality of intimacy and engagement necessary to promote relationships. The point is not that virtual learning communities require only synchronous communication technologies, but rather that synchronous communication technologies are better suited to providing the immediacy, intimacy, negotiation and engagement that nurtures the development of a sense of community among learners.

\section{Questions Raised by Virtual Learning Communities}

Virtual learning communities don't just happen; they are designed and built. They are not unique in the sense that they are different from other types of learning communities. Rather. they attempt to mimic the vibrancy of "real" learning communities by using technologies in a way that promotes the development of 
relationships among learners. If educators choose to support the development of virtual learning communities, a number of new issues arise concerning management, pedagogy and content liability. On the surface, the most imposing barrier appears to be financial. Technology requires hardware, software, and access, and these elements can be expensive However, other issues are just as important, and in some cases, more difficult to deal with in supporting this type of intervention. Most organizational and instructional design thinking has been constructed on premises that discrete learning activities occur in some temporal sequence and within groups "housed" within specific organization structures. We present a few of these issues in the form of questions which educators will need to address.

- What are the shared values and commitments that enable a virtual learning community to become a community of mind?

- What are the patterns of mutual obligations and responsibilities that emerge in virtual learning communities?

- How can teaching and learning settings be arranged to support learning communities that extend beyond the walls of schools?

- What kinds of pre-service preparation and professional development opportunities do educators require to adopt new roles demanded by technology-based interventions?

\section{Concluding Thoughts}

In summary, the construction of virtual learning communities is a purposeful act, and one that requires an intimate knowledge of the needs of the participants, and the capabilities of emerging communication technologies and design concepts. Building virtual learning communities invites one way to think about finding some answers to curricular challenges faced by most educators and especially those in rural communities today. Some of the strongest objections to many distance education initiatives charge that they are expensive, they are difficult to manage, and they fail to provide the type of interaction and engagement among students necessary to promote a high level of learning. At the same time, rural educators are confronted with the option of supporting a smaller local school population by supplementing the curriculum with traditional distance education courses, versus closing smaller schools and moving students to larger centres which can support a broader range of specialized programs. The argument between the benefits of smaller schools and larger programs continues to percolate and the argument carries implications for all education organizations and virtual community builders today:

In order to build a caring community, students need continuity in their school residence. They should stay in one school building for longer than two or three years. Children need time to settle in, to become responsible for their physical surroundings, to take part in maintaining a caring community. When we have to choose between highly specialized programs for a narrow range and a continuity of place, we should choose the latter. Continuity of place is easier to achieve in smaller schools. (Noddings, 1992) 
The choice between specialized programs and continuity of time or place presents a false dichotomy; it is an either-or proposition that deserves to be challenged. Of course, using technology to support the development of virtual learning communities will not provide definitive solutions to the many challenges faced by schools. Many students are technologically literate, and many already participate in informal virtual learning communities, yet curricular problems persist. However, educators are challenged to find ways of using technology that are consistent with constructivist changes underway in the schools and school administration, and recognize that virtual learning communities can contribute to the way we respond to those challenges.

We must be able to catch the ball that the child throws to us, and toss it back to them in a way that makes them want to continue the game (of learning) with us... developing, inventing new games as we go along. (Filipinni. 1990)

\section{References}

Aristotle (1997). Book VIII. Nichomachean ethics. In J. Porter, Ed.), classics in political philosophy (2nd ed.). Scarborough, Ontario: Prentice-Hall.

Bellah, R.N. (1985). Habits of the heart: individualism andcommitment in american life. New York: Harper Collins.

Ely, D., Foley, A., Freeman, W. \& Scheel, N. (1995). Trends in educational technology 1991. In G. Anlgin (Ed.) Instructional technology: Past, present, future (2nd ed.). Englewood Cliffs, NJ: Libraries Unlimited. (34-60).

Etzioni, A. (1992). The moral dimension: toward a new economics. New York, NY: Free Press.

Fillipinni, T. (1990). Introduction to the Reggio approach. Symposium presentation. National Association for the Education of Young Children. Washington, DC: Author.

Heckscher , C., and Donellon, A.M. (Eds.) (1994). The post-bureaucratic organization. London, UK: Sage Publications.

Honderich, T.M. (Ed.). (1995). Oxford companion to philosophy. Oxford, UK: Bath Press.

Nohria, N., and Berkley, J.D. (1994). The virtual organization: bureaucracy, technology and the implosion of control. In Heckscher, C., and Donnellon,

A.M. (Eds.). The post-bureaucratic organization. London, UK: Sage Publications. 108-128.

Senge, P.M. (1994). The fifth discipline. New York, NY: Currency.

Sergiovanni, T.J. (1996). Leadership for the schoolhouse. San Francisco, CA: Jossey-Bass.

Stone, A.S. (1992). Will the real body please stand up? Boundary stories about virtual cultures. In M. Benedikt (Ed.). Cyberspace: First steps. Cambridge, MA: MIT Press. 81-1 18.

Tonnies, F. (1957). Gemeinschaft und gesellschaft. [Community and Society]. (C.P. Loomis, Ed. and Trans.), New York, NY: Harper Collins.

Prawat, R.S. (1992). From individual differences to learning communities-our 
changing focus. Educational Leadership. 28(l), 9-13.

Noddings, N., (1992). The challenge to care in schools. New York, NY: Teachers College.

\section{$\overline{\text { AUTHORS }}$}

Eugene G. Kowch is a Ph.D. candidate in the Department of Educational Administration at the University of Saskatchewan.

Richard A. Schwier is a Professor of Educational Communications and Technology in the Department of Curriculum Studies at the University of Saskatchewan.

An earlier version of this paper was originally presented at the Second National Congress on Rural Education, Saskatoon, Saskatchewan, February 2 1, 1997.

1998 by E.G. Kowch and R.A. Schwier 


\title{
Towards Optimising the Organisational and Educational Effectiveness of Videoconferencing for Vocational Education
}

\author{
Stephen Towers \\ Roy Lundin \\ Patrick Maguire
}

\begin{abstract}
Videoconferencing provides an example of a technology which has been consistently inconsistent for organisations generally. and teaching purposes specifically. Educational administrators appear to be particularly susceptible to seductive overtures ofthe technology, only to be perplexed and potentially disheartened by the reality.

This paper has four aims (1) to identify and understand some of the myths and assist educational organisations investigating videoconferencing; (2) to examine some of the similarities and differences between videoconferencing and more traditional educational practices (including face-to-face and open learning/distance education); (3) to identify and discuss potential influences for organisations during adoption and implementation. in an attempt to understand underlying process contributing to the understandings associated with the videoconferencing: and (4) to pragmatically address issues associated with the administration and management of videoconferencing systems for education and training providers.

The literature associatcd with videoconferencing together with practical experience and the findings from an intensive case study of one vocational teaching organisation adopting and implementing videoconferencing will be used to illustrate and discuss issues,
\end{abstract}

Résumé: La vrdéoconférence constitue l'exemple d'une technologie qui n'a de constant que son Inconstance, pour les organisations de façon générale et pour l'enseignement de façon particulkre. Les administrateurs de l'enseignement semblent portés à se laisser séduire par l'apparence de la technologie, pour se retrouver perplexes. votre découragés, par la réalité plus tard

Cet article a quatre buts. (1) d'identifier et comprendre quelques-uns des mythes d'une part, et venir en aide aux organisations éducationnelles qui contemplent l'utilisation de la vtdéoconférence d'autre part; (2) d'étudier les différences et les similitudes entre la vidéoconférence et les pratiques pédagogiques plus traditionnelles (y compris l'enseignement en face a face et la pédagogie ouverte ou l'éducation à distance), (3) d'identifier et discuter des Influences potentielles pour les organisations pendant l'adoption et l'implantation de la vidéoconférence et ce. dans le but de comprendre le processus fondamental qui sous-tend le savon associé à la vidéoconférence; et (4) d'étudier, de façon pragmatique, les questions liées à I'administratton et à la gestion de la vidéoconférence pour les fournisseurs d'éducation et de formation

La documcntation sur la vidéoconférence, les expériences pratiques ainsi que les conclusions d'une étude de cas Intensive impliquant une organisation d'enseignement professionnel tiendront lieu d'illustrations et d'éléments de discussion.

\section{Introduction}

Communication and information technologies are often an enigma, deceiving decision makers and designers by either failing to satisfy innovation goals, or by 
influencing social settings in unanticipated ways. Videoconferencing' provides an example of one such technology that has been "consistently inconsistent" for organisations. The sparse and fragmented literature on videoconferencing provides a lengthy history of a technology which has appeared to offer substantial communication potential, but has habitually failed to meet anticipated benefits, disappointing adopting organisations (Towers and Hearn, 1995). Egido (1988) described videoconferencing as a synonym for marketing disaster. (p. 14)

Despite a history ofahnost three decades, there has been relatively little research on this technology, particularly concerning its adoption and implementation by organisations. Most research has concentrated on the comparison of videoconferencing to other teleconferencing media usually considering face-toface as a "defacto" standard (see for example, Champness, 1973, Radford et al., 1994; Simpson, Pugh and Parchman, 1992, 1993). Understanding its adoption and implementation by organisation has mainly been undertaken by post hoc. large scale, quantitative studies or descriptive case studies and evaluation reports.

The development of strategies for organisations adopting and implementing videoconferencing have assumed a relationship between teleconferencing and Rogers' (1983) diffusion theory (for example, Johansen, 1984; Noor AL-Deen, 1988; Karnes,

1990; Jacoby, 199 I : Earon, 1993). Although Rogers ( 1983) logico-linear approach is appealing for such applications, there is considerable debate over its general utility (Markus and Robey, 1988; Lewis and Seibold. 1993) for videoconferencing (Karnes, 1990; Sanderson, 1992, pp. 20 1-2 12; Earon, 1993, p. 24).

In order to address the inadequacies of prior research, this paper will elucidate some common misconceptions and influences which contribute to understanding how organisations adopt and use videoconferencing for teaching purposes

\section{Perspectives}

The authors have developed this paper from three perspectives:

I. An educational perspective

An educational perspective of videoconferencing provides a critical account of the users of videoconferencing within the educational context (Lundin and Donker, 1992; Lundin. Simpson. Hansford and Skippington, 1995). It was from this perspective that many of the myths were identified. Data were gathered using questionnaires, observations and interviews of the users.

2. An organisational perspective

An organisational perspective sought to understand and explain the processes sustaining and reinforcing the myths. The research methodology relied on a case study approach (Towers, 1997) which examined the entire context of the organisation adopting and implementing videoconferencing. Data were gathered from decision makers, designers (those responsible for designing the macro implementation strategy), local implementers (those responsible for 
implementing videoconferencing locally), and users. Data were gathered using interviews, document analysis and observations. A structuration perspective(3) (Towers and Hearn, 1996) provided the theoretical framework to explicate the interactions which constitute certain human action during the adoption and implementation of videoconferencing. One major difference between the case study and the educational perspective was that the former sought to understand the processes associated with adoption and implementation of the technology within a holistic framework, whereas the latter concentrated on the users of the technology.

3. Pragmatic/technical perspective

A pragmatic/technical perspective provides workable responses in an attempt to provide strategies to address the myths within the organisation.

Within these perspectives we identify and address 13 myths associated with videoconferencing. The following list should not be considered comprehensive, but it does represent the common inconsistencies between perception and reality found in our research and practical experience. We should also emphasise that in certain circumstances and contexts some of these myths may actually meet expectations. However, from our investigations these were the exception rather than the rule.

\section{Research setting}

While the following discussion draws upon research in other organisations, the main context for the paper is an organisation under the pseudonym TrainingDept.

TrainingDept is a large, geographically distributed state government organisation responsible for the delivery of post secondary vocational education and training courses to the community. II 1994, TrainingDept was the major provider in the state at approximately 60 sites. TrainingDept 's organisational structure comprised a corporate executive called State Office located at the state's capital and decentralised semi-autonomous Institutes distributed throughout the state. Most Institutes constituted a main campus (the location of the majority of each Institute's management and operation) and a number of smaller campuses which varied significantly in distance (from a few kilometres to many hundreds of kilometres) from the main campus.

Institutes usually provided education and training programs to the community through face-to-face teaching in classroom settings. Institutes were physically established in major population centres with limited facilities at campuses in communities with smaller populations. Distribution ofeducational disciplines was predominantly a function of population, with the greatest range of topics located at or around the state's capital city. Access to disciplines otherthan those at Institutes or their campuses was achieved through people moving to the place where it was offered or teachers moving to the location of demand. Unless anticipated student 
demand was high, sustained or specially funded, the former situation normally dominated. One Institute (called Open Institute) specialised in providing correspondence or distance education materials as an alternative. Disciplines available from Open Institute were limited and the delivery mode primarily used printed materials and the postal system.

\section{Exploring the myths of videoconferencing}

Myth 1

Videoconferencing is a direct substitute for, and more productive than, face-toface teaching

Assumptions of the substitutability and increased productivity of videoconferencing are the keystone upon which all the myths presented in this paper are constructed and reinforced. In structuration terms these are described as institutional properties which mutually shape and reinforce human agency. They are diffused and sustained by many sources of human action including vendors, consultants, technical staff, designers, implementers and management.

Consequently, implementation design(4), including information dissemination activities, are saturated with perceptions or interpretive schemes(5) of substitutability and increased productivity (such as printed materials, videotapes and demonstrations). Increased productivity as an interpretive scheme permeated implementation activities, manifested as tangible (for example, travel time and cost) and intangible (for example, relieving travel fatigue) advantages over other communication options, particularly travel-mediated communication.

The centrality of this myth will become evident as each of the other myths are discussed. Furthermore, the myths are not discrete and there is considerable overlap and mutual reinforcement between them.

\section{Myth 2}

Teachers have the requisite knowledge and skill base for videoconferencing and quickly adapt to it.

Finding:

This myth is developed from the assumption that videoconferencing is a direct substitute for face-to-face communication. The premise that teachers will be able to easily transfer or acquire the requisite knowledge and skills to videoconferencing significantly influences action and events during its adoption and implementation.

At Training Dept, teachers found videoconferencing required different knowledge, skills and practices from their previous experiences for both classroom teachers and open learning teachers. Some face-to-fade teachers reported that videoconferencing required a didactic teaching approach, and were reluctant to use traditional participative activities because they felt that they should be active for the entire time they were connected to another site. Some teachers found the placement of the camera and associated technology restricted their movement, i.e. 
they were unable to move around the room or make large arm movements. It provided little relative advantage over previous practices and had high dissonance (Normann, 1971).

Furthermore, teachers were being allocated the maximum work loads in established teaching modes as a consequence of the environmental (competition) and organisational contexts (decreasing resources). Moreover, other changes occurring at TrainingDept, coming from devolution of responsibilities (meetings and resource management), resulted in additional duties for teachers. The impact of these issues in shaping the human context for videoconferencing teaching was significant across TrainingDept. As one implementer remarked:

A few teachers are keen (on videoconferencing) if there is support and release (from other duties), but there is too much else to do, plus normal teaching. People have enough on their plate and don't need something new, so they avoid it. They are not negative, but don't have time for training and development.

Teachers were undertaking additional activities (such as the allocation of resources, marketing and promotion and administrative procedures) which for established teaching modes were completed as a matter of course, usually by others in the organisation.

\section{Myth 3}

Videoconferencing economically aggregates disparate students.

Finding:

This myth is based on the perception of increased productivity by being able to teach to many locations simultaneously with the one teacher. For example, at TrainingDept one of the aims of videoconferencing was to deliver more costeffectively education and training programs to rural and remote locations by aggregating small groups of students in different locations. However, videoconferencing delivery proved to be only cost-effective if there were large numbers of students in each location because of the high cost of the equipment and high telecommunication charges. In addition the availability of appropriate telecommunications infrastructure in many rural and remote locations did not exist or were expensive to install.

\section{Myth 4}

Distance education institutions will be the most effective users of videoconferencing

Finding:

An underlying premise of decision makers was the compatibility of videoconferencing with distance education, and in particular the Open Institute 
within this state system. However, organisational and human contexts associated with distance education were developed around a print-based, teacher-student asynchronous and independent delivery mode, whereas videoconferencing required teachers to interact with students in real time.

Videoconferencing was expected to be highly compatible at Open Institute because is operations were considered to be sympathetic with many of the goals for teaching by videoconferencing (delivery to geographically separated locations). Furthermore, the Director of Open Institute had allocated substantial resources for videoconferencing including a change agent (released half time from other duties) and financial resources available for any related purpose including providing human resources. However, videoconferencing was incompatible with the norms of both students and teachers.

For students, videoconferencing restricted their traditional flexibility and control over their learning. Some students had enrolled at Open Institute because it enabled them to undertake the course at a time, pace and place of their own choosing. Videoconferencing required them to be at a place at a certain time to be taught at a certain pace.

For teachers, videoconferencing required different skills. Previous student contact had been asynchronous by mail, or interaction mediated by telephone, with occasional face-to-face meetings. Live student contact was usually on a oneto-one basis. Learning content was provided by printed materials with the teacher acting as a mentor and tutor. Videoconferencing teaching required teachers to interact with groups of students. Furthermore, teachers believed that their present mode of instruction was more equitable to students, whereas videoconferencing was only available to students with access to facilities. Organisational structures at Open Institute had developed around these norms and there were no existing mechanisms for easily coordinating, aggregating or requiring students to attend videoconferencing sessions.

\section{Myth 5}

All locations within the organisation will have the same response to videoconferencing

Finding:

Lewis and Seibold's (1993, p. 347) framework proposed that variation in the forms of the innovation-in-use (across individuals or groups of users) was the result of users' structuring interactions related to the innovation. Access to different modalities of structure within certain locales influenced utilisation of videoconferencing and appropriation of sub-innovations. For example, identification of the peculiar cultural differences within an organisation (Karnes, 1990; Van Maanen and Barley, 1985) appeared important to understand the fidelity of innovation. 
This situation was evident at TrainingDept where only four of the sixteen sites regularly used videoconferencing for teaching purposes because of the peculiarities of the local innovation context. The remaining sites made some use of videoconferencing for teaching purposes, but these were irregular events resulting from activities initiated by State Office or the Steering Committee, use by early adopters or exceptional circumstances. Using videoconferencing for most sites was incompatible with organisational and human contexts or offered no apparent relative advantage over previous practices.

The following examples are noteworthy to illustrate the different influences on the adoption of videoconferencing.

The first example, Institute 1, had two sites. Site I was the main campus and Site 2 was a recently established campus located over 100 kilometres from the main campus. Site 2 had organised training and education programs using local staff as well as teachers travelling (driving) from Site 1. These two sites represented what was referred to in the evaluation report (Lundin et al., 1995) as a 'natural setting' for the use of this technology. That is, videoconferencing was compatible with the norms of decision makers and teachers and provided relative advantage. The Institute Director had recently established the campus at Site 2 and was motivated by community demand to extend the number of courses. Videoconferencing offered a potential mechanism for increasing the number of courses offered to students at an affordable cost. Although learning to use videoconferencing and preparing courses were considered time consuming for teachers, so too was the time required to drive between campuses for each lesson. Teachers were more willing to provide courses via videoconferencing because travel was not required. Replacing driving with videoconferencing also lowered costs of delivering programs. In addition, the new courses were taught by casual teachers who were motivated to teach by videoconferencing because it provided them with employment.

The importance of the local culture is demonstrated when the previous example is compared with another pair of sites where videoconferencing was not used regularly. At Institute 2, three sites had videoconferencing facilities installed. Site A and Site B, several hundred kilometres apart, had established a good pattern of usage. Furthermore, Site A had also expected to use videoconferencing with another intrainstitutional site (Site C) which was about 100 kilometres away. However, Site $\mathrm{C}$ had been established for several years and had its own teaching staff living in, and employed from, the local area. It rarely used anyone from the main campus at Site A. Staff at Site C had the perception that the campus' future was uncertain and the emergence of videoconferencing appeared to substantiate rumours that it would be closed. At the time videoconferencing arrived, the teachers' work load was fully allocated so that any videoconferencing 
teaching was an additional duty. Furthermore, prospective students living at Site $\mathrm{C}$ but wanting to undertake courses at Site A had a history of travelling to Site A.

The inconsistencies in the findings presented here illustrate the importance of relative advantage to the local culture. These examples suggested that acceptance of videoconferencing was facilitated where it was interpreted to be sympathetic with the culture of the local innovation context and relative advantage. Conversely videoconferencing tended to be rejected where it was considered to be antithetical and there was little relative advantage.

\section{Myth 6}

Videoconferencing will be a catalyst for change - including creating new and improved communication patterns, organisation structures. skills and knowledge

Finding:

Orlikowski and Yates (1994) indicated that the introduction of communication technologies had the propensity to influence the genre (socially recognised types of communicative actions) of organisational communication. Modifications, as a consequence of videoconferencing, at TrainingDept were the new and increased numbers of communication participants in administrative meetings and teaching by videoconferencing at four of the 16 videoconferencing sites.

Emulation of existing communication systems simultaneously facilitated and constrained utility. Users tended to appropriate aspects of videoconferencing where it was compatible and directly substitutable for existing practices (administration meetings) while rejecting other more radical aspects (for example. teaching and multipoint videoconferencing).

Supporting the literature associated with teleconferencing (Egido, 1990; Gowan and Downs, 1994; Kraemer, 1982; Nuwer, 1989; Svenning, 1982), videoconferencing was accepted and utilised where communication opportunities existed or were latent. Modalities of structure available to human agents appeared to shape the use of videoconferencing rather than modify or create new structures as suggested by some of the literature (Barley, 1986; Poole and DeSanctis, 1990; Orlikowski, 1992). That is, videoconferencing was accepted where:

communication increased between temporally and spatially separated participants, for example, established teaching between sites where videoconferencing offered significant benefits over travel;

face-to-face communication could not justify resources for travel, for example, administrative meetings;

it provided additional benefits over alternative options, for example, travel fatigue, more regular contact, visual communication, meeting community training demand, and lack of resources; and 
existing communication skills and knowledge were consistent with the use of the technology, for example, unequivocal meetings and meetings where participants were known to one another.

Videoconferencing was rejected (actively or passively) where it was antithetical to modalities of structure associated with communication. That is. videoconferencing was rejected where:

other communication modes were considered superior and resources were available; for example, travel mediated teaching or existing teaching priorities.

- new communication protocols were required; for example, training, multipoint videoconferences, and equivocal meetings.

\section{Myth 7}

\section{A fully automated system is a substitute jor user's skills and knowledge} Finding:

For some organisation" implementation strategies centred on the interface between the technology and the users and reinforced the need to ensure substitutability ofexisting communication skills, knowledge and practices. There was a temptation to mitigate perceived problems with the organisational and human contexts by relying on technical solutions to mirror existing structures. Uncertainty served to compound this activity and motivated the implementation design to focus on a human or technological interface between users and the technology. Orlikowski et al. (1995, p. 425) described this type of human interface as chauffeurs who 'relieve users of the need to interact directly with the technology'.

Technological interfaces were purposely developed by designers to restrict the scope of new skills and knowledge required by intended users for videoconferencing. The development of a technical interface reinforced the strategies selected for implementation to focus on the technology. Implementation activities centred on the selection and installation of equipment (Kyrish, 1989). Orientation to the technical context concentrated information gathering activities on technical information (equipment specifications and purchasing procedures) which tended to de-emphasise other contexts or subsume them.

At TrainingDept, the implementation team comprised two groups, (1) a system wide administration/management group and (2) a small group within each Institute. No teachers were represented on the administration/management group. For the majority of teachers and those within the second group, their first involvement was during training delivered shortly after the installation of equipment at the Institute. Although there was an attempt to design systems that had a low technological impact on the teacher, the majority of resources were expended on “off the shelf' equipment, not on modifications or people. This was partly because the majority of the funding provided was capital funding for equipment, not recurrent funding for operational support. As one decision maker said, 
They are offering us $\$ X$ and if we don't grab it and spend it on boxes-we lose it. Myth 8

Organisations have the skills and knowledge to make effective decisions about adopting and implementing videoconferencing

Finding:

Decision makers generally believe they have the necessary resources and skills to adopt and implement videoconferencing within their organisation because it is perceived to be substitutive with existing communication. Furthermore, the activities and strategies decision makers and designers undertake during initiation' tend to reinforce this perception.

For example, at TrainingDept during the early stages of adopting videoconferencing, decision makers visited TrainingDept2, a similar organisation in another state. Videoconferencing was interpreted by decision makers to be an innovation that was moderately routine and offered positive relative advantage. Shortly after becoming aware of videoconferencing, it was perceived by decision makers as a potentially useful innovation that would enhance TrainingDept 's competitiveness by improving service provision and resource productivity. In particular, videoconferencing was considered by decision makers to (1) provide the capacity to deliver education and training programs to any point throughout TrainingDept's system of Institutes, (2) aggregate groups of students across several locations and (3) deliver training to the workplace of other organisations/industry. Decision makers considered that videoconferencing was compatible with existing infrastructure and could be implemented provided the capital for videoconferencing equipment was available. As stated by one decision maker who became responsible for implementation:

Teachers will take to this like ducks to water.

Myth 9

Staff responsible for the organisation's information and communications systems are the most appropriate to make decisions about adoption and implementation.

Finding:

As indicated by Johansen (1984) there is a tendency for organisations thinking about videoconferencing to delegate adoption and implementation activities to staffresponsible for communications information technology roles. Even with the best intentions, such staff tend to be biased towards the technology, concentrate on technical aspects and omit human, organisational and environmental issues.

The activity associated with initiation is delegated to designer(s), concentrating responsibility in a few human agents in each organisation. Perceptions of substitutability and increased productivity were readily transported from decision makers to designers. These perceptions were sympathetic, or at least not antithetical, to their existing interpretive schemes and were fundamental to human activity. 
For example, at TrainingDept interpretive schemes encouraging the focus of activity on the technology rather than organisational or human issues were directly compatible with the designers' (who came from an information and communication technology background) existing interpretive schemes.

Designers were the de facto information gatekeepers who dominated and shaped decision making. Information sought and provided by designers influenced the decision to adopt. At TrainingDept biased information gathering appeared unintentional, mutually determined by available modalities of structure(8), but at another organisation information was manipulated for specific audiences.

(We) were somewhat biased towards videoconferencing, obtaining appropriate information to justify it to management.

Myth 10

The only difference between point to point videoconferencing obtaining appropriate information to justify it to management

Finding:

The same modalities which tended to facilitate appropriation of (routine) pointto-point videoconferencing operated in the rejection of more radical multipoint videoconferencing (such as the maintenance of existing communication skills and knowledge). Leonard-Barton and Sinha (1993) similarly found that matching current practices may inhibit the development of new user skills or organisational structures. During early stages of adoption, the face-to-face component of videoconferencing was invoked to promote it and to constitute the perception of its substitutability. During implementation. it was relatively congruent with pointto-point videoconferencing where there was continuous presence'. but it was not actualised with multipoint conferencing where only certain participants (current and previous speakers) could see one another. For example, multipoint videoconferences were considered inappropriate for many users at TrainingDept because of the difference in communication practice (delays in switching between sites, restricted to viewing one site, technical unreliability) and additional knowledge required to connect sites together. Interstingly, this myth was seen as a fallacy by decision makers and designers at TrainingDept and extra training and administrative processes were available. However, the technology was unable to meet expectations because they had not mastered point to point videoconferencing.

Myth 11

Videoconferencing willfit in with existing orgunisational structures Finding:

The substitutability of videoconferencing contributes to decision makers' assumptions that videoconferencing could be accommodated within existing organisational infrastructure. Excluding a small proportion of resources for training and promotional activities, extra resources (finances) were principally designated 
for equipment procurement. Other resources (including the staff responsible for implementation) were obtained from existing sources. This requisite acted as a caveat to circumscribe information gathering and decision making parameters which in turn constrained implementation design.

Implementation activities assumed the innovation was directly substitutable or congruent with existing organisational structures. Implementers opted for training which imparted few skills, knowledge or attitudes to users in the beliefthat existing practices would transfer to videoconferencing. For example, training was didactic and delivered in a one-off short "dose" over a few hours or days. Implementation mediation(10) was constrained by implementation design which assumed videoconferencing would be compatible with the environmental context (students and wider community), organisational context (procedures and policies), technical context (ISDN infrastructure) and human context (skills, knowledge and practices). The actual nature of videoconferencing emerged after implementation. Videoconferencing usage for teaching purposes was incompatible with the innovation context at most Institutes.

Teaching by videoconferencing was found to be significantly different from environmental and organisational contexts for twelve of the sixteen sites. Detailed examples are presented in Table 1.

\section{Myth 12}

\section{Existing human resource structures are all you need}

Finding:

FindingReliance on existing infrastructure constrained the selection of the local implementers on the basis of available positions considered substitutable rather than the anticipated skills, knowledge and attitudes required for videoconferencing. For example, TrainingDept allocated videoconferencing responsibilities to teachers or office staff with existing duties. Personnel were selected on the basis of position, personal interest or the manager's discretion. In most cases videoconferencing responsibilities were subordinate to, or were subsumed within, other existing duties of the staff. Implementers received little or no initial support and training to facilitate the implementation of videoconferencing at the local site. The type and magnitude of activity was determined by their level of resourcefulness, commitment to the technology, competing duties and self motivation.

\section{Myth 13}

\section{Participative decision makingfacilitates videoconferencing}

Finding:

According to the literature, participation enables innovation through increasing fit between the users and the innovation (Lewis and Seibold, 1993; Nord and Tucker, 1987); by facilitating communication of the innovation; and by gaining the support of intended users (Dean, 1987; Mintzberg, Raisinhani and Theoreti, 1976). While 

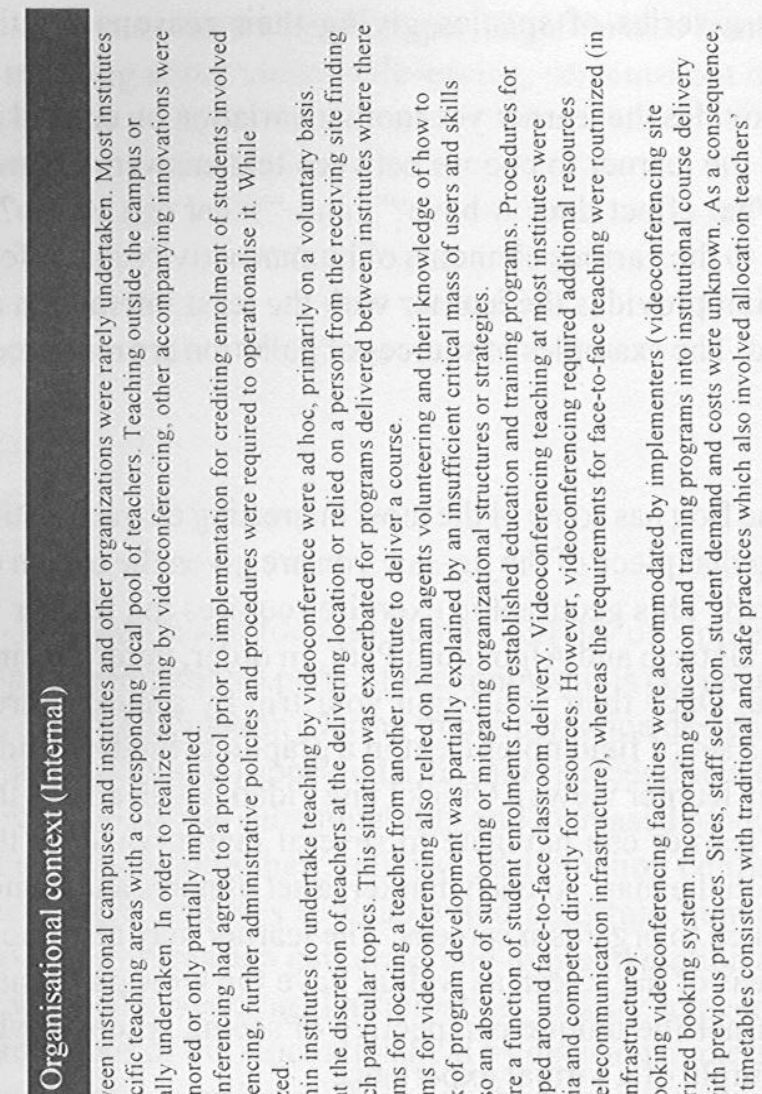

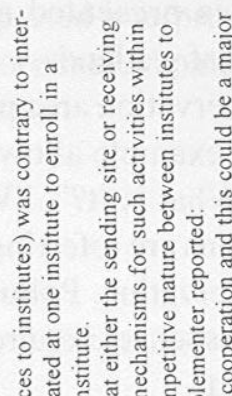

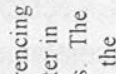

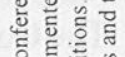

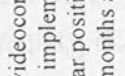

पे

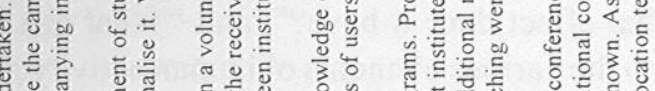

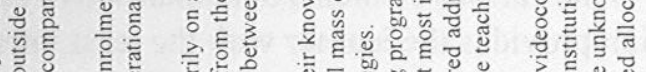

E

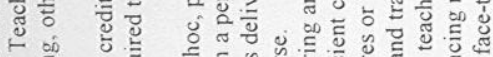

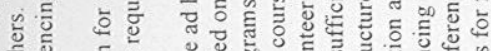

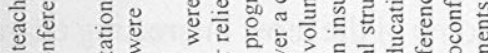

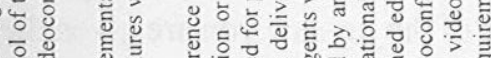

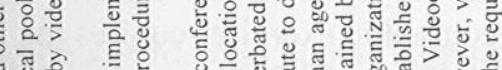

을 牙

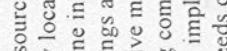

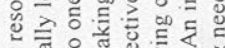

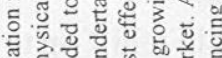

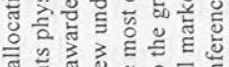

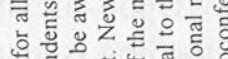

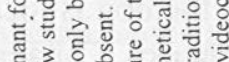

है है

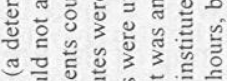

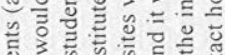

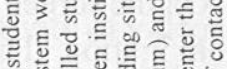

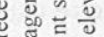

응

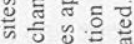

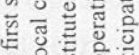
要空

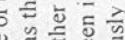

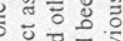

政卷

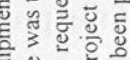

형은 훙후

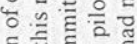

등 है융

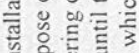

绻政

西

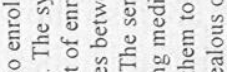

응 원

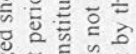

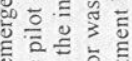

in

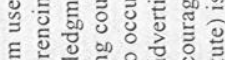

돈

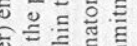

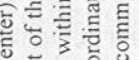

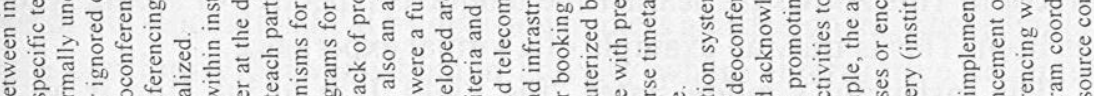

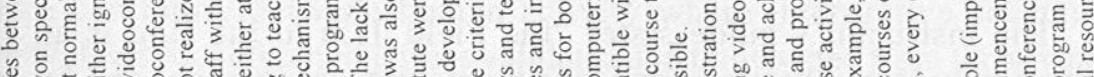

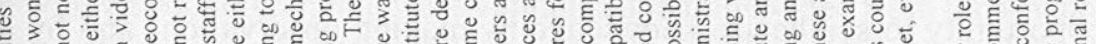

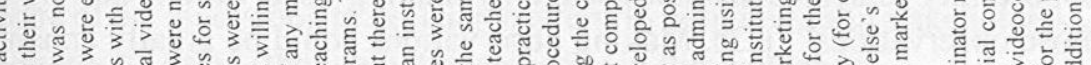

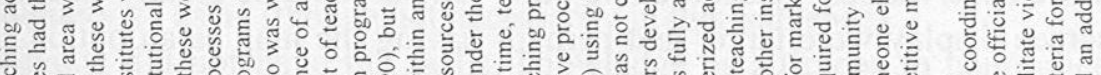

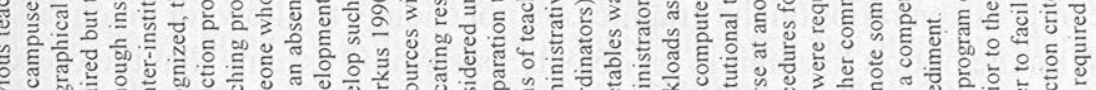

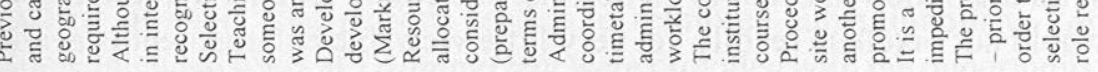

त ले

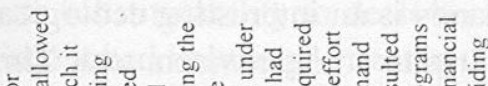

욜

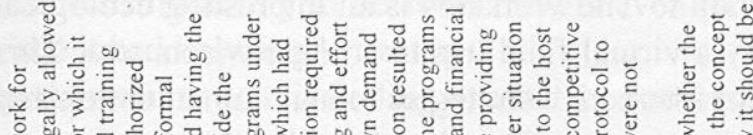

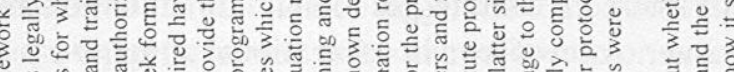
年

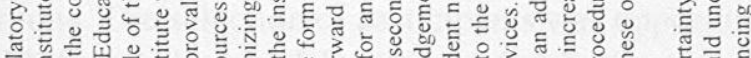

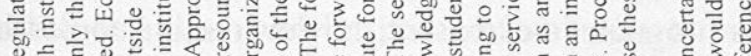

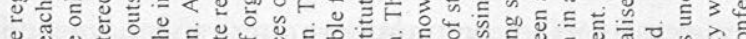
Ð 。

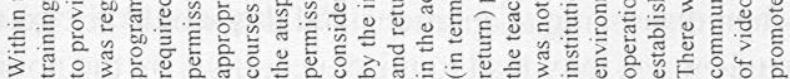


this section is presented as a series of species giving their reasons for the conservation of wetlands.

The Conservation area provides the learner yet another variation on control as each graphic example allows the learner to choose between text answers to three questions: "What is it?", "What effect does it have?", and "What can we do?". These questions are referring to the various elements of human activity that affect wetland conservation. Pollution provides the learner with the least interaction as there are no responses required. The examples of sources of pollution are reinforced by pop-up text.

\section{The Field Trip}

The virtual Field Trip to the Bog has some of the most interesting characteristics of the program. Upon clicking that piece of the jig-saw you are given the option of seeing whcrc the bog is located. This geographic exercise requires the learner to find North America, Canada, Ontario and Algonquin Park, in order, before seeing an aerial view of Cloud Lake. Once their you begin your trip by seeing a three dimensional map of the area, a set of field notes (text in a graphical binder), and a small screen. On the screen the learner views a QuickTime video which allows the control and navigation. The learner can navigate to several markers within the movie, which are also shown on the map. At each marker, a set of notes and names of species which are hyperlinked to organism screens. The learner may also zoom in and out to view specific areas of the screen as well as have the view pan in any direction. This allows the learner the unique perspective of seeing where she/he has been. This is truly an example of a virtual experience.

The instructor's guide states "the Field Trip to the Bog is an excellent opportunity to synthesize knowledge by making observations and by analyzing those observations" (p.3). Making observations could be greatly enhanced if the screen display were larger and perhaps having the map as an option. Also the compression ratios on the graphics are not enough to allow for much enlargement. With the option to zoom in on objects, one would assume that the objects would not pixellate readily yet very little viewable enlargement is available.

\section{Conclusion}

The Digital Field Trip to The Wetlands is an interesting ecological package which is highlighted by a virtual field trip to a bog environment. This package utilizes a wide variety of interactive strategies to maintain attention and promote engagement with the learner. A few flaws in navigational strategy exist primarily due to the misguided assumption that student's always read the textual material supplied.

The content of this program is extensive, however some topics have been omitted or edited out. For example, the programmers chose to ignore a wide variety of wetland species when discussing adaptations and this would not go unnoticed by the experienced student and may lead to misconceptions by the novice. Many content areas have detailed textual accounts and highly interactive learning 
these aspects were identified, participation also transported interpretive schemes or meaning about videoconferencing, screened out more radical parts of the

innovation and focused human activity on implementation design for routine (highly compatible) parts of the innovations (Leonard-Barton and Sinha, 1993).

User participation (during implementation design or involvement in short trials or demonstrations) appeared to be more successful in disseminating and reinforcing perceptions of the substitutability and increased productivity ofvideoconferencing rather than testing their validity. Participation confirmed the legitimacy of these interpretive schemes to enable and constrain human activity (such as decision making, information gathering and implementation design) to form selected uses of videoconferencing. Participation usually appeared insufficient to challenge perceptions of the innovation held by decision makers and designers. Accordingly, there was a continuity between human activity where interpretive schemes associated with videoconferencing were validated and transported from those who became aware of the innovation to decision makers, to designers (and stakeholders), to implementers, to users (though not necessarily in this sequence).

Participants did not have the skills, knowledge or attitudes to contradict perceptions of the technology provided by decision makers and implementers. Demonstrations or short trial periods tended to reinforce substitutability. For example, some intended users at TrainingDept were provided with the opportunity to trial videoconferencing between two locations over a short period which reinforced its substitutability to decision makers even though it failed for these locations once it had been implemented.

An important caveat on this finding was that the participation from the intended users in our investigations was not comprehensive or even representative. It was usually restricted to specific events or providing feedback from limited demonstrations. The selection of participants was opportunistic or assumed to be representative and they had limited and sometimes controlled exposure to videoconferencing (through verbal descriptions, demonstrations of technical capabilities or short trial periods). 


\section{Understanding perpetuation of myths}

Of particular interest are the underlying processes which create and maintain these myths during adoption and implementation. The research analysis demonstrated the centrality of substitutability and increased productivity as interpretive schemes to shape initiation and implementation. This section discusses and attempts to explain how these interpretive schemes develop and are sustained as well as their ramifications for implementation.

Other research efforts have also indicated the importance of substitutability and increased productivity schemes for organisations adopting communication and information technologies (Barley, 1986; Tyre and Orlikowski, 1994). For instance, Kraut et al. (1994) found that human agents adopted new technology when the direct or indirect benefits outweighed the costs. The centrality and mutuality of perceptions of substitutability and increased productivity were most significantly demonstrated at TrainingDept where videoconferencing was considered substitutable for existing practices whereas only a few sites were able to derive an apparent tangible productivity dividend from implementation. Justification for decisions involved financial (cost-benefit), interpersonal and political components (Dean, 1987), though financial substantiation was most important. Without a perceived direct (financial) benefit to both organisations. in order to rationalise the resources, substitution was insufficient to proceed.

Even though Shulman et al. (1990) criticised decisions to adopt communication technologies on these assumptions, they remain an important motivating force. The resilience and dominance of perceptions of substitutability and increased productivity were maintained and continued to influence human activity even though designers had gathered information which disputed their validity. In a comparable example. Tyre and Orlikowski (1994, p. 108) found thatproductivity improvement, as a consequence of the innovation, became more important than the organisation's original objectives.

Substitutability and productivity have also featured prominently in the literature associated with videoconferencing. The identification of these interpretive schemes as important motivational forces was not new. Jacoby's (1991, pp. 113-114) synthesis of the videoconferencing literature indicated that substitutability was fundamental for researchers and practitioners in the 1970s while productivity emerged during the 1980s. Substitutability and increased productivity were often found in studies as variables explaining adoption or acceptance (see Noor AlDeen, 1988; Pease, 1988). Even though contemporary emphasis has shifted to increased productivity, substitutability is still foundational and advocated. For example, Fussell and Benimoff (1995) recently rejected assertions that videoconferencing could not substitute for face-to-face in-person communication. They argued that substitution of videoconferencing for face-to-face in-person communication was only constrained by technical limitations.

Productivity was initially substantiated by analyses which calculated the anticipated savings gained from substituting videoconferencing for travel. Even 
though there was doubt about the validity of this claim (Earon, 1993) it continued to remain an important justification of adoption provided by experts and vendors (see Nuwer, 1989; PictureTeI, 1995; Smith, 1995). Productivity has also expanded to include enhancing competitiveness through enabling more timely and effective communication (Jacoby, 1991) and by increasing communication opportunities (Egido, 1990).

Although researchers and experts associated with videoconferencing have a lengthy history of cautioning potential adopters of the efficacy of perceptions of substitutability and increased productivity (Johansen, 1984; Krauss and Fussell, 1990; Nuwer, 1989; Olgren and Parker, 1983; Short et al., 1976) these interpretive schemes persist, continue to be evoked and are widely disseminated by researchers, evaluators, vendors and the popular press. The findings confirmed that these schemes are easily accessible and quickly become assumptions for decision makers and influence how and why videoconferencing is adopted and implemented. Congruent with this finding, Mintzberg (1978, p. 942) argued that decision making and strategy formation can be self confirming resulting from the interaction between the environment and the organisational context.

A possible explanation for the tenacity of these schemes and their effortless assimilation is offered by Weick (1990) who suggested that new technologies create problems in sense making for managers and users because they appear to provide several possible or plausible interpretations and are therefore subject to misunderstandings. The original intentions for the innovation are developed out of human agents' knowledge and understanding of the innovation, potential use and the context. The innovation is, by its definition, novel to the organisation so the information gathered about the innovation (including the process of gathering) and the way it is understood with respect to the organisational context is arguably a key influence that underpins and determines the actions of decision makers, designers, implementers and users.

Other literature similarly indicated that human agents draw upon familiar knowledge and skills when confronted by a novel context (Krauss and Fussell, 1990; Van Maanen, 1984). For example, perceptions form because videoconferencing is assumed to be substitutable with existing face-to-face interaction (Cohen, 1984; Johansen, 1984; Stubbs and Burnham, 1990) and this assumption is reinforced by limited exposure (such as demonstrations, didactic training, biased information). Shulman et al. (1990) argued that researchers and practitioners have been preoccupied with substitution and increased productivity and considered them as innate attributes associated with communication technologies. Furthermore, they posited that designers conceived intended users as being similar to themselves and tended to concentrate on the technical infrastructure and ignore the human infrastructure. Therefore, the technology's role is confined to the 'narrowness of the frame, false conceptions of the process and false images of potential users' (Shulman et al., 1990, p. 174).

In their investigation of organisational absorptive capacity, Cohen and Levinthal (1990, p. 128) asserted that innovation performance is 'history - or path dependent'. 
Consistent with their work, the findings suggested that prior knowledge may be a prerequisite to identify, understand and use new knowledge which becomes fundamental to an organisation's ability to exploit this knowledge. Consequently, organisations may not have the requisite prior experiences to critically evaluate interpretive schemes associated with the perceived nature of the innovation.

It was also found that a low level of uncertainty shaped information processing to reinforce these schemes. Harianto and Pennings (1994) considered that an organisation's absorptive capacity may be influenced by perceptions of uncertainty. Zaltman et al. (1973, p. 54) similarly suggested decision makers experience different kinds of certainty towards the innovation depending upon the information available concerning the consequence for implementation alternatives. The literature indicated that perceptions of the innovation potentially impacted on uncertainty (Daft et al., 1987, p. 357; Weick, 1990) which may be related to the level of risk reduction through information gathering (Galbraith, 1973; Tornatzky and Fleischer, 1990, p. 165). Consequently, where videoconferencing was understood to be routine (substitutive) and offer relative advantage (increased productivity) then uncertainty was low thereby constraining the scope of information gathering. Uncertainty decreased when the information resulting from this activity confirmed these schemes (such as the cost benefit analysis). From this line of reasoning, perceptions may result in misalignment in implementation design (Leonard-Barton, 1988). It seemed natural for those involved that further human activity should concentrate on technical issues (Kyrish, 1989) -the acquisition and installation of the hardware and software - rather than on the validation of interpretive schemes associated with the perceived nature of the innovation. Moreover, the perceived nature of the innovation was reinforced by participants during initiation (decision makers, designers and others) tending to focus on technical issues and ignoring the communication context (Svenning and Ruchinskas, .1984). That is, omitting organisational (Keen, 1990, p. 300) and user issues (Fulk et al., 1990, p. 134; Ellis, 1993). Tornatzky and Fleischer (I 990, p. 205) classified this emphasis as technocentric. According to Tornatzky and Fleischer (1990, p. 207), the technocentric view has a rationalist perspective of the implementation process without consideration for any social technologies. The orientation toward this perspective at the organisations studied in this research was reinforced by the selection of designers from communication or information systems sections of the organisation (Thach and Woodman, 1994).

The successful mediation of these interpretive schemes may be in part explained by the transfer of mutual knowledge between communication participants (Krauss and Fussell, 1990) used to convey meaning about videoconferencing to others. That is, the speakers must formulate their contributions with an awareness of what their addressee does and does not know' (p. 112). This was problematic, particularly if there was considerable difference between the levels of knowledge of the communication participants or both participants were novices. Communication between novices tended to simplify the message through more descriptive dialogue 
(for example, information about videoconferencing relied on descriptions based on perceptions of substitutability and increased productivity).

Fulk's (Fulk et al., 1995; Fulk et al., 1990) theory of social influence is normally applied to the implementation of the technology into a social setting, but it could also be applied to initiation whereby interpretive schemes about the innovation are transported between human agents - particularly the decision makers, designers and intended users or stakeholders. There were indications that perceptions of the innovation for those involved during initiation were determined by co-worker attitudes, statements and behaviours (meetings, correspondence and disseminated information) and vicarious learning (demonstrations and didactic training). This could help explain the dissemination of the perceptions of substitutability and increased productivity in ambiguous situations and why greater exposure to the technology reduced the efficacy of these schemes (Fulk et al., 1990, p. 125). Drawing upon Collin's (1992, p. 93) contention that emotional energy was a fundamental modality motivating human activity, videoconferencing appeared to be an innovation that facilitated high enthusiasm and spontaneity for those involved during initiation. Even though each of the designers stated his initial objectivity in relation to videoconferencing, there was a tendency for those involved in the activity to become ardent supporters. This was manifested in the selective provision of information, high expectations and an increase in the scope of selected uses.

The findings of our research and experience supported those who argued organisational information processing should increase as technologies become less routine (Keller, 1994, p. 167) and match the design and structure of the organisation (Cohen and Levinthal, 1990; Daft and Lengel, 1984,1986; Keller, 1994; Tushman and Nadler, 1986). But these views have not previously considered that understanding of the radicalness of the innovation may be inhibited by available structural properties" and human activity. The findings indicated that it was difficult for designers to identify radical sub-innovations once an innovation was assumed to be routine and there was less uncertainty. Subsequent human activity during initiation tended to confirm this perception through information gathering.

In summary, the findings indicated that perceptions of the innovation are formed early during initiation and these tend to shape human activity during initiation while being mutually reinforced by that action. The literature indicated that interpretive schemes of substitutability and increased productivity served as dominant, but imperfect, lenses for considering innovations generally and videoconferencing specifically. Understanding unfamiliar technologies relies on prior knowledge for interpretation. However, technologies which are recondite (Weick, 1990) may constrain the frame of interpretation which may contribute to false understanding (interpretive schemes) and misinterpretations. The transportation of such interpretive schemes may be similarly transported to others participating during initiation who lack mutual knowledge. Greater uncertainty associated with these interpretive schemes appears to increase the scope of information gathering. 


\section{Pragmatic considerations}

Our findings and analysis also have policy and practical implications for organisations adopting and implementing videoconferencing.

\section{Perceptions of substitutability and increased productivity}

The findings indicated that the interpretive schemes associated with the perceived nature of the innovation were acquired early during initiation. In addition these interpretive schemes were pervasive and both enabling and constraining. Therefore, one of the most important implications is the need to identify and understand interpretive schemes associated with the perceived nature of the innovation and how they can influence the innovation process in order to reduce misalignment between initiation and implementation (Leonard-Barton, 1988).

\section{Education and training applications}

Videoconferencing for education and training purposes appeared to be a radical innovation. Though it is tempting for policy makers to consider videoconferencing as a potential mechanism for reducing educational delivery costs (Ellis, 1993), it is unlikely that it will achieve such expectations in the short to medium term. Structural properties associated with the delivery of education and training are firmly grounded in face-to-face delivery (see Gooley and Towers, 1996; Lundin. 1992). Education and training programs using videoconferencing appear to require new structures of signification (skills and knowledge for teachers), control (organisational procedures and different resources) and legitimation (community acceptance). Otherwise they are likely to fail or be relegated to research projects or peripheral applications.

\section{Videoconferencing training}

In this study, training provided in an intensive session before use was quickly forgotten. Similarly, Liguori (1985) found that general training of prospective videoconferencing users was insufficient and resulted in low demand whereas one-to-one instruction with those about to use videoconferencing appeared to be more successful. Videoconferencing for applications which rely on advanced technical skills or involved equivocal communication perhaps required different training needs (Earon, 1993) -for example, formal and informal training initiatives or an apprentice style (Goodman and Griffith, 1991). Training delivered in a short concentrated block appears to have little efficacy for assisting teachers to modify their skills and practices to use videoconferencing. In particular the trainer may be faced with considerable resentment if participants are not prepared or previously informed about videoconferencing.

Successful communication using videoconferencing is considered to require new and different skills (Fussell and Benimoff, 1995; Kydd and Ferry, 1994). In this respect, there seems to be considerable merit for Hildebrand's (1995) suggestion 
thattertiary institutions should include videoconferencing within their curriculum to facilitate understanding of its communication properties.

\section{Participation during innovation}

The findings and conclusions of this study have ramifications for participation and how it is managed. The types of participation evident in these case studies tended to provide limited utility for implementation and were more successful in transporting interpretive schemes about the nature of the innovation.

Participation during initiation across the four case studies ranged from nil for many locales, to demonstrations, to limited trials for certain applications. Even short trial periods by organisations proved artificial and unrepresentative of applications or the multiplicity of structures available to intended users. This was illustrated at TrainingDept where the retrospective justification for the decision to adopt videoconferencing for education purposes was based on its evaluation over one week between an Institute and a remotely located company. Yet the actual teaching use of videoconferencing at the Institute proved limited and did not emerge when videoconferencing was nnplemented.

Participation may require a longer period of exposure to the technology in representative situational and functional contexts with users from different locales". Lee (1989) argued that ideally, the selection of participants should include a combination of cases that are likely to produce similar and contrary results. Such an approach highlights the importance of 'minimising and maximising differences among groups to discover patterns and identify potential theoretical properties' (Johnson. 1990, p. 24).

Participation in videoconferencing appears complex because human agents had a lack of mutual knowledge with respect to the technology. It may be important to ensure participants are active rather than passive and to include those who are not the most conducive to the task or do not understand the technology rather than those who are 'accommodating, cooperative and do not disagree or challenge the intended system, the design models, or the process' (Beath and Orlikowski, 1994, p. 369). On the other hand, such inclusion or a longer exposure may also mitigate opportunities to appropriate more radical sub-innovation which may benefit the organisation in the longer term (as indicated by Tyre and Orlikowski, 1994). Alternatively, participation may not be as important or useful as some have thought" and is only one way of ascertaining knowledge about sympathetic and antithetic interpretive schemes. The confusion in the literature demonstrates that this is an area which warrants further research.

\section{Reinforcing communication structures}

Videoconferencing has the potential to assist with some of the contemporary imperatives of education and training, in particular the need to provide programs to participants between locations separated in time or space. However, structures were the consequence of existing and emerging opportunities related to the fundamental activities of groups/individuals rather than the presence of 
videoconferencing. As recommended by Frost and Egri (1991, p. 230), 'it is not safe to assume that the best or superior inventions - innovations will survive on their own merits'.

\section{Multipoint videoconferencing}

Multipoint videoconferencing was particularly problematic for users and often did not meet expectations. Users require new skills and knowledge to communicate in multipoint videoconferences (through training). The use of splitscreens to view all sites simultaneously could be more consistent with existing skills and knowledge to address this problem.

\section{Access to resources}

Videoconferencing impacts upon human as well as financial resources. The findings from this research indicated the importance of sufficient organisational slack in human resources to administer and support videoconferencing rather than the tendency to incorporate responsibilities within substantive duties.

\section{Human and technical interface}

A common conclusion of videoconferencing researchers and experts is exemplified by the following quotation:

A practitioner interested in implementing video conferencmg should be certain that the medium is both easy to use and simple to operate and as effective as face-to-face business meetings (Pease, 1988, p. 186).

The findings from this study supported the view that a simple technological and human interface facilitated acceptance of videoconferencing, but they also indicated that interpretive schemes acquired early during implementation were pervasive and foundational to subsequent use. As previously stated, there may be only a small window of opportunity for change (Tyre and Orlikowski, 1994). If the goal for innovation includes the usage of more advanced features of videoconferencing or equivocal communication, then purposeful intervention and creation of new structural properties may be required -for example, training that upgrades skills and incentives or disincentives.

\section{Time}

Initiation and implementation of videoconferencing were potentially time consuming. The time period for innovation must be sufficiently flexible to enable informed decisions and to allow appropriate implementation design and mediation.

\section{Conclusion}

The original motivation of this paper was to identify, understand and address the inconsistent findings regarding the implementation of videoconferencing. In this light its main contribution has been to peel back the skin of this superficially 
straightforward technology to reveal the underlying social complexity engaged in its deployment.

An innovation such as videoconferencing constitutes structural properties which become available to human agents. These are drawn upon as modalities of structure or act as a catalyst to evoke other structural properties. The analysis of such interaction is essential for understanding and explaining how structural properties are sustained, modified or diminished in the diffusion of effective videoconferencing.

It is important to restate that the interactions contained within each myth were differentiated to aid analysis and discussion. The interaction and demarcation between human action and structural properties were in reality complex and interdependent with the social setting. As suggested by Williams and Rice (1983, p. 204):

The new technologies are not, in an overall sense, inherently impersonal or personal. Our main challenge is to understand better their distinguishing qualities and, even more so, to develop our stylistic and persuasive strategies for their most effective use.

\section{References}

Barley, S. R. (1986). Technology as an occasion for structuring evidence from observations of CT scanners and the social order of radiology departments, Administrative Science Quarterly, 31, 78-108.

Barley, S. R. (1990). The alignment of technology and structure through roles and networks, Administrative Science Quarterly, 35, 61 - 103.

Beath, C. M. \& Orlikowski, W. J. (1994). The contradictory structure of systems development methodologies: Deconstructing the IS-User relationship in information engineering, Information Systems Research, 5(4) 350-377.

Bikson, T. K., Gutek, B. A.\& Mankin, D. A. (1981). Implementation of information technology in office settings: review of relevant literature. Rand, Santa Monica.

Champness, B. G. (1973). Attitudes toward person-person communications media, Human Factors, 15(5), 437-447.

Cohen, I. J. (1989). Structuration theory: Anthony Giddens and the constitution of social life, Macmillan, Hampshire.

Cohen, W. M. and Levinthal, D. A. (1990). Absorptive capacity: a new perspective in learning and innovation, Administrative Science QuarterZy.35, 128-1 52.

Collins, R. (1992). The romanticism of agency/structure versus the analysis of micro/macro, Current Sociology, 40, 77-97.

Contractor, N. S. \& Seibold, D. R. (1993). Theoretical frameworks for the study of structuring processes in group decision support systems: adaptive structuration theory and self-organizing systems theory. Human Communication Research, 528-563. 
Daft, R. L. \& Lengel, R. H. (1984). Information richness: a new approach to managerial behaviour and organization design, in Research in organisational behavior, (eds.) B. Staw \& L. Cummings, JAI Press, Greenwich, pp. 191233.

Daft, R. L. \& Lengel, R. H. (1986). A proposed integration among organizational information requirements, media richness, and structural design. Management Science, 26(5), 554-571.

Dean, J. W. (1987). Deciding to innovate: howfirms justify advanced technology. Ballinger Publishing Company, Cambridge.

Earon, A. S. (1993). Adoption of videoconferencing in education and business, PhD thesis, UMI: 9414152, Boston College, The Graduate School of Arts and Science, Boston.

Egido, C. (1988) Videoconferencing as a technology to support group work: A review of its failure, Association for Computing Machinery, 13, 13-24.

Egido, C. (1990) Teleconferencing as a technology to support cooperative work: its possibilities and limitations in intellectual teamwork: social and technological foundations of cooperative work, (eds.) J. Galegher, R. E. Kraut and C. Egido, Lawrence Erlbaum Associated, New Jersey, pp. 35 1-370.

Ellis, M. E. (1993). Uncovering presence: what adult participants say enhances instructional videoconferencing, PhD thesis, UMI: 9411936, The Ohio State University.

Frost, P. J. \& Egri, C. P. (1991). The political process of innovation, Research in organizational behavior, 13. 229-295.

Fulk, J., Schmitz, J. \& Ryu, D. (1995). Cognitive elements in the social construction of technology. Management Communication Quarterly, 8(3), 259-288.

Fulk, J., Schmitz, J. \& Steinfield, C. W. (1990). A social influence model of technology use, in Organisations and communication technology, (eds.) J. Fulk and C. Steinfield, Sage, Newbury Park.

Fussell, S. R. \& Benimoff, I. (1995). Social and cognitive processes in interpersonal communication: implications for advanced telecommunications technologies, Human Factors, 37(2), 228-250.

Galbraith, J. (1973). Designing complex organizations, Addison Wesley, Massachusetts.

Giddens, A. (1979). Central problems in social theory.- action, structure and contradiction in social analysis, University of California Press. Berkeley.

Giddens, A. (1984). The constitution of society, University of California Press, Berkeley.

Goodman P. S. \& Griffith. T. L. (1991). A process approach to the implementation of new technology, Journal of Engineering and Technology Management, $8,261-285$.

Gooley, A. \& Towers, S. (1996). Turning ocean liners: managing interactive technology innovation, Proceedings of the third international interactive multimedia symposium, Perth, pp. 
Gowan, J. A. \& Downs, J. M. (1994). Video conferencing human-machine interface: a field study, Information and management, 27,341-356.

Harianto, F. \& Pennings, J. M. (1994). Technological convergence and scope of organizational innovation, Research Policy, 23,293-304.

Hildebrand, J. E. (1995). Videoconferencing in the business curriculum, Journal of Business and Technical Communication 9(2), 228-240.

Jacoby, J. P. (1991). The development and adoption of videoconferencing technology for business applications: an historical perspective, masters thesis, UMI 1S49399, California State University, Fresno.

Johansen, R. (1984). Teleconferencing and beyond: communications in the office of the future, McGraw Hill, New York.

Johnson, J. C. (1990). Selecting ethnographic informants, Sage, California.

Karnes, H. L. (1990). Factors influencing the adoption of teleconferencing technology in the university-based teaching hospital, D.Ed. dissertation, UMI 91 17702, The Pennsylvania State University.

Keller, R. T. (1994). Technology-information processing fit and the performance of R\&D project groups: a test of contingency theory, Academy of Management Journal, 37(l), 167- 179 .

Keen, P. G. W. (1990). Telecommunications and organizational choice, in organisations and communication technology, (eds.) J. Fulk and C. Steinfield, Sage, Newbury Park, pp. 295-3 13.

Kraemer, K. L. (1982). Telecommunications/transportation substitution and energy, Telecommunications Policy, 6, 39-59.

Krauss, R. M. \& Fussel. S. R. (1990). Mutual knowledge and communicative effectiveness, in intellectual teamwork: social and technological foundations ofcooperative work, (eds.) J. Galegher, R. E. Kraut and C. Egido, Lawrence Erl baum Associated, New Jersey, 111- 145.

Kraut, R. E., Rice, R. E., Cool, C. \& Fish, R. S. (1994). Life and death of a videophone: individual, structural and social influences on the use of a new communication medium, paper presented at the International Communication Conference, Sydney, NSW, June.

Kydd, C. T. \& Ferry, D. L. (1994). Managerial use of video conferencing, Information and Management, 27,369-375.

Kyrish, S. (1989). The technology and implementation of motion video conferencing, in the teleconferencing managers guide, (ed.) K. Hansell, Knowledge Industry Publications Inc. White Plains, New York, pp. 85-104.

Leonard-Barton, D. (1988). Implementation and mutual adaptation of technology and organisation, Research Policy, I7, 25 1-267.

Leonard-Barton, D. \& Sinha, D. K. (1993). Developer-user interaction and user satisfaction in internal technology transfer, Academy of Management Journal, 36(5), 1125-1139.

Lewis, L. K. \& Seibold, D. R. (1993). Innovation modification during intraorganizational adoption, Academy of Management Review, l\&2), 322-354. 
Liguori, C. (1985). A videoteleconferencing success story, in Teleconferencing and electronic communications: applications, technologies and human factors Volume IV. (eds.) L. A. Parker and C. H. Olgren, University of Wisconsin Extension Centre for Interactive Programs, Madison, pp. 186-1 89.

Lee, A. S. (1989). A scientific methodology for MIS case studies, MIS Quarterly, March, pp. 33-50.

Lundin, R. (1992). Non-Traditional modes of delivery in higher education using state-of-the-art technologies. Report for the modes of delivery review of the Department of Employment, Education and Training (DEET) and the National Board of Employment, Education and Training (NBEET), unpub.

Lundin, R. \& Donker, A. (1992). Queensland videoconference trial.. report of the queensland government trial of compressed videoconferencing between brisbane and townsville. Media and Information Services, Brisbane.

Lundin, P., Skippington, P.. Simpson, T. \& Hansford, B. (1994). Videolinq evaluation.. interim report August 1994, TAFE Queensland, Brisbane.

Lundin, P., Simpson, T., Hansford, B. \& Skippington, P. (1995). Videolinq evaluation: final report, Queensland University of Technology, Brisbane.

Markus, M. L. (1990). Toward a "critical mass" theory of interactive media, in Organisations andcommunication technology, (eds.) J. Fulk \& C. Steinfield, Sage, Newbury Park, pp. 194-236.

Markus, M. L. \& Robey, D. (1988). Information technology and organizational change: causal structure in theory and research, Management Science, 34(5), 583-598.

Mintzberg, H. (1978). Patterns in strategy formation, Management Science, 24 (9) $934-94 s$.

Mintzberg, H., Raisinhani, D. \& Theoreti, A. (1976). The structure of "unstructured" decision processes, Administrative Science Quarterly, 21, 246275.

Noor Al-Deen, H. S. (1988). Corporate teleconferencing: audio, video and computer, $\mathrm{PhD}$ thesis, UMI 8812373, State University of New York at Buffalo.

Nord, W. R. \& Tucker, S. (1987). Implementing routine andradical innovations. Lexington Books, Lexington Massachusetts.

Normann. R. (197 1). Organisational innovativeness: product variability and reorientation, Administrative Science Quarterly, 16, 203-215.

Nuwer, J. (1989). Getting to the bottom line, in The teleconferencing managers guide, (ed.) K. Hansell, Knowledge Industry Publications Inc, Whtie Plains, New York, pp. 125-1 42.

Olgren, C. H. \& Parker, L. A. (1983). Teleconferencing technology and applications, Artech House Inc, USA.

Orlikowski, W. J. (1992). The duality of technology: rethinking the concept of technology in organizations, Organizational Science, 3, 398-427.

Orlikowski, W. J. Yates, J. (1994). Genre repertoire: the structuring of communicative practices in organisations. Administrative Science Quarterly, 39, 541-574. 
Orlikowski. W. J.. Yates. J., Okamura, K. \& Fujimoto, M. (1995). Shaping electronic communication: the metastructuring of technology in the context of use. Organization Science. 6(4), 423-444.

Pease, P. S. (1988). Factors influencing the use of video conferencing for organizational communications, $\mathrm{PhD}$ thesis, University of California.

PictureTel (1995). Applications discovery guide: corporate training, PictureTel, Massachusetts.

Poole, M. S. \& DeSanctis. G. (1990). Understanding the use of group decision support systems: the theory of adaptive structuration. in Organisations and conznzunication technology, eds. J. Fulk and C. Steinfield, Sage. Newbury Park. pp. 173- 193.

Radford, G. P., Morganstern, B. F., McMickle, C. W. \& Lehr. J. K. (1994). The impacts of four conferencing formats on the efficiency and quality of small group decision making in a laboratory experimental setting, Telematics and Informatics, 11(2), 97- 109.

Rogers, E. M. (1983). Diffusions of innovations, 3rd edn, Free Press, New York. Sewell, W. H. 1992, A theory of structure: duality, agency, and transformation, American Journal of Sociology, 98( 1 ), 1-29.

Short, J., Williams, E. \& Christie. G. (1976). The social psychology of telecommunications, John Wiley and Sons, London.

Shulman, A. D., Penman, R. \& Sless, D. (1990). Putting Information technology in its place: organizational communication and the human Interface. In Applied socialpsychology and organizational settings, (ed.) J. S. Carroll, Lawrence Erlbaum Associates, New Jersey.

Simpson, H., Pugh. L. \& Parchman, S. (1992). An experimental two-way video teletraining system: design, development and evaluation, Distance Education, I2(2). 209-231.

Simpson, H., Pugh, L. \& Parchman, S. (1993). Empirical comparison of alternative instructional TV technologies, Distance Education, 14( 1 ), 147- 165.

Smith, M. (1995). Video conferencing: the personal touch, OSP, December/January, pp. 38-39.

Stubbs, S. T. \& Burnham, B. R. (1990). An instrument for evaluating effectiveness of electronic distance education systems, The American Journal of Distance Education, 4(3), 2537.

Svenning, L. L. (1982). Predispositions towards a telecommunication innovation: The influence of individual. contextual. and innovation factors on attitudes, intentions, and projections toward video-conferencing, $\mathrm{PhD}$ thesis, University of Southern California.

Svenning, L. L. \& Ruchinskas, J. E. (1984). Organizational teleconferencing, in The new media: communication, research and technology. ed. R. E. Rice and Associates, Sage, Beverley Hills, pp. 217-248.

Towers, S. (1996). Diffusing videoconferencing in government organisations: a structurational analysis, PhD Thesis, Queensland University of Technology, 
Brisbane, unpub.

Thach, L. \& Woodman, R. W. (1994). Organizational change and information technology: managing on the edge of cyberspace, Organizational dynamics, summer, pp. 30-46.

Tornatzky, L. G. \& Fleischer, M. (1990). The Process of Technological Innovation, Lexington Books, Massachusetts.

Towers, S. (1997). Diffusing videoconferencing in government organisations: a structurational analysis, $\mathrm{PhD}$ Thesis, Brisbane.

Towers, S. \& Hearn, G. (1995). Videoconferencing: towards explaining plementation failure, paper presented to the Confercncc of Australian and New Zealand Communication Association, Edith Cowan University, June 5-7, Perth.

Towers, S. \& Hearn, G. (1996). Conceptualising innovation in organisations: a structurationist perspective, paper presented to the Conference of Australian and New Zealand Communication Association, July 10-12. Brisbane.

Tushman, M. \& Nadler, D. (1986). Organizing for innovation, California Management Review, 26(3), 74-92.

Tyre, M. J. \& Orlikowski, W. J. (1994). Windows of opportunity: temporal patterns of technological adaptation in organisations, Organisational Science, 5( 1), 98-1 18.

Van Maanen, J. ( 1984). Doing new things in old ways: the chains of socialization, in College and university organization, (ed.) J. L. Bess, New York University Press, New York.

Van Maanen, J. \& Barley, S. R. (1985). Cultural organization: fragments of a theory, in Organisational culture, (eds.) P. J. Frost, L. F. Moore, M. R. Louis, C. C. Lunberg and J. Martin, Sage, Beverley Hills, pp. 3 1-53.

Weick, K. E. (1990). Technology as equivoque: sensemaking in new technologies, in Technology and organizations, (eds.) P. S. Goodman, L. S. Sproull and Associates, Jossey-Bass, San Francisco.

Williams, F. \& Rice, R. E. (1983). Communication research and the new media technologies, in Communication Yearbook 7, (ed.) R. N. Bostrom, Sage, Beverley Hills.

Zaltman, G., Duncan, R.\& Holbeck, J. (1973). Innovations and organizations, Wiley-interscience, NewYork.

$\overline{\text { AUTHORS }}$

Stephen Towers is the Deputy Chief Executive of the Queensland Open Learning Network at the Queensland University of Technology.

Roy Lundin is a Senior Lecturer at the Queensland University of Technology. Patrick is a consultant at the Queensland University of Technology. 


\section{Notes}

(1) The authors wish to acknowledge the financial sponsorship and assistance for this research provided by the Queensland Government Department of Public Works and Housing (formerly the Administrative Services Department).

(2) Videoconferencing in this paper refers to Broom-based= videoconferencing systems using digital compression.

(3) Structuration requires unique conceptions of structures and systems than are usually offered by the literature. Structures are manifested as structural properties that incorporate rules and resources or Assets of transformation relations@ that human actors draw upon in their dayto-day interaction (Giddens. 1979,1984). Structuration indicates how structural properties are regularised through actors use of rules and resources. Structures and systems become reifed over time and through use have $>$ objective $=$ like properties. However. structural properties only exist while being reproduced and have no reality independent of the social setting within which they are used.

(4) Implementation design is defined for this research as thstratcgies and activities for introducing and disseminating the innovation to a specific context.

(5) Interpretive schemes are the basic reserves of communal knowledge routinely utilised by human agents during interaction that enable meaning to be mediated and maintained within a specific context (Orlikowski, 1992).

(6) This finding was not evident at TrainingDept but was common for other organisations (see Towers, 1997).

(7)Initiation and implementation are terms used to differentrate the activities before and after the innovation is physically present in the organisation.

(8)Modalities of structure are accessed by human agents to recursively link structural properties and human action in the reproduction of systems of interaction (Giddens, 1984). Modalities may include interpretive schemes. communication norms and traditions.

(9)Participants can see each location at all times.

(10)Mediation of the innovation is concerned with the purposeful diffusion of the innovation to the specific innovation context, primarily the users during implementation

(11) Structural properties are developed through regular patterns of interacton established through ongoing use of human agents knowledge and reflexive action. These structures are then drawn upon by organisational members for subsequent action which fortifies and sustains the patterns. The continuous interactions are called agency (Giddens 1979, p. 55) and the reciprocal reinforcement is called duality of structure (Orlikowski, 1992).

(12)Svenning and Ruchinskas (1984) call this a fair trial use. 
(13) For example, contrast the conclusions of Bikson, Gutek and Mankin,1981, p. 13 with Wagner, 1994. 


\title{
Information Clues in Topical Web Searches. Is the Web Message Getting Through?
}

\author{
Mary Ann Epp
}

\begin{abstract}
When creators produce Web pages, they aim to attract searchers to their site. In many cases. the searchers are given the URL site's address. It is, therefore, not difficult to find the page provided the searcher has typed the URL address correctly and the site still exists at the time of searching. But what happens if the searcher does not know the address and is searching a topic or subject? Surfing for information on a topic can be frustrating and time consuming for the searcher. In a study on Web searches, this researcher encountered and recorded many difficulties in identifying information clues to Web sites from the document representation in the hit list. T'he study was based on research for completion of the Masters thesis in Library and Information Studies at the University of British Columbia in 1997. Implications for Web page design are discussed.
\end{abstract}

Résumé: Une recherche dans Internet pour de l'information sur un sujet peut devenir pour une expérience frustrante qui prend du temps En étudiant des outils de recherche, le chercheur a retrouvé et noté de nombreuses difficultés dans I'identification des indices informattonnels dans la représentation des documents des pages Web Le but de cette étude était d'identifier. de décrue et d'analyser la représentation des documents dans les listes d'occurrence relevées dans les recherches effectuées par quatre outils de recherche: AltaVista, InfoSeek Ultra. Lycos et Open Text Index À ces outils de recherche on avait accordé la tâche de fane une recherche sur les trots sujets suivants. l'édition sur commande, l'éducation à distance et le graphisme en relief. Le chercheur a constaté que plusieurs des pages Web figurant dans le résumé des résultats de la recherche affichaient peu ou pas d'indices informattonnels sur l'auteur. l'organisation. le mode électronique ou le pays d'origine. Une discussion des implications de l'etude pour la conception de pages Web est fournie

The purpose of the study was to identify, describe and analyze the document representations of sites revealed in the hit list of the searches conducted by four search engines: AltaVista, InfoSeek Ultra, Lycos, and Open Text Index. Three subjects were selected to be searched through the search engines: custom publishing, distance education, and tactile graphies.

Document representations are surrogates for the documents themselves and are sometimes called information containers (Lancaster, 1993). They are the first sets of words the searcher sees after completing a search using one of the Web's search engines, or browsers. The title and summary mirror the first part of the Web page itself. The surrogates provide the abbreviated package of information from which a searcher selects the whole document to view.

The Problem

Because the information on the Internet is extensive, unorganized, and not presented in a standardized manner, searchers encounter considerable difficulty in identifying 
and evaluating the resources on the Web. Publishing documents on the Web does not require adherence to any guidelines or standards for bibliographic presentation or content. The Web has no comprehensive classification scheme to group similar documents together, nor does it have a collocation system to differentiate the versions of a title or gather together the works by the same author. The absence of publishing standards dealing with presentation of content in bibliographic terms makes it difficult, at times, to identify the information clues such as the source, author, authority, type of publication, and provenance of a publication.

The research problem or questions for this study focused on the presence or absence of information clues in the document reprcscntation of material retrieved by search engines on the Web. Do the various fields of information in the document representations reveal many clues? How can a Web page designer increase the access by including the clues in the design?

\section{Assumptions}

The researcher assumed that a large number of information clues would assist the searcher in selecting relevant documents in the set of hits retrieved by the search engines. Conversely, it was assumed that a small number of clues would make it more difficult for searchers to find relevant documents.

The content of the Web is an ever changing phenomenon. Web documents appear, disappear, and change. The functional capabilities of the search engines are constantly evolving as well. Search engines that are highly rated in one research article may not be the same ones selected in another article, or at another time.

\section{Operational Definitions}

Search engines are defined as computer program applications developed to assist the users to search the World Wide Web. The four search engines, AltaVista Vista, InfoSeek Ultra, Lycos, and Open Text Index were selected because they represented four of the most common search tools covering a large number of Web documents.

Document representation is defined as the display information shown by a Web search engine in the hit list, or the container of the information. which includes various information fields, such as the title, the URL (Uniform Resource Locator), or address of the Web site, and the summary. A sample of a document representation is shown in Figure 1.

Information clues are defined as identifiers that may include the author, the source, the organization, the topic or subject, the country of origin, and the electronic genre of information.

The electronic genre is defined as the format of the information. Electronic genres are listed as the "resource type" in the Dublin Core Metadata Element Set (1997). For the purposes of this study, electronic gem-es were limited to print formats. The most common electronic genres found through this study were indexes or links, advertisements, research articles or reports, and directories. 


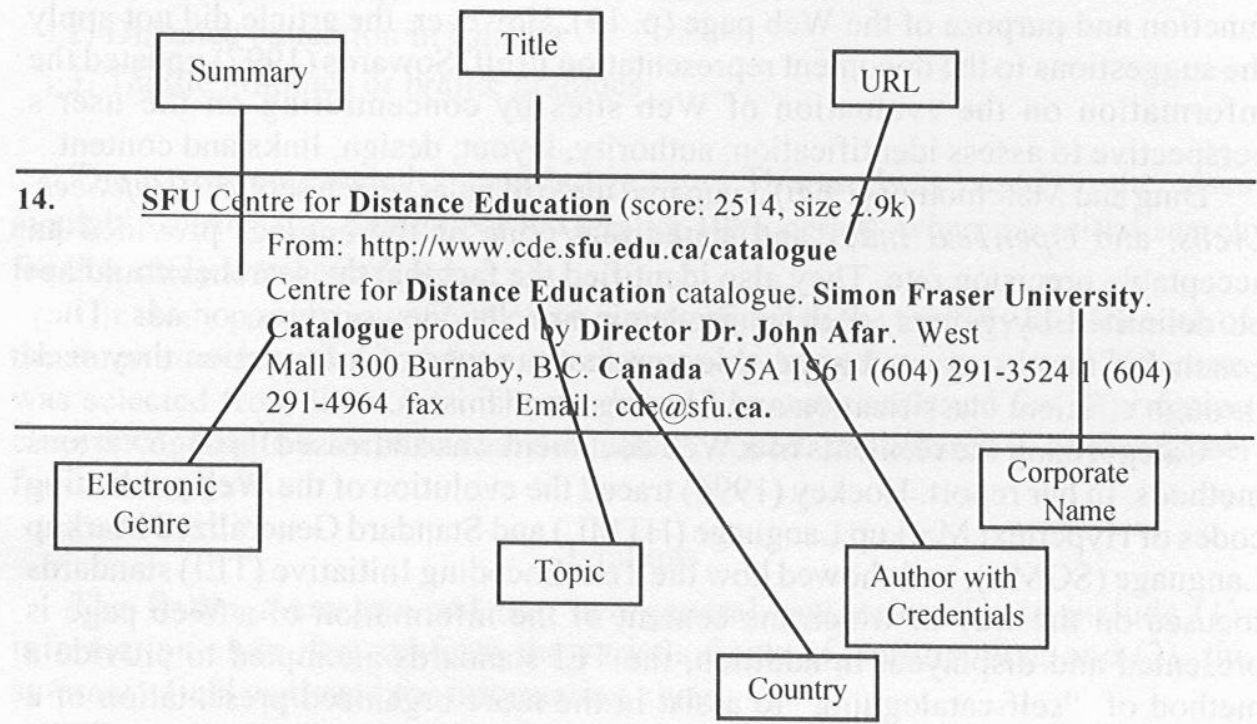

Figure 1: Sample of a document representation

\section{Literature Search}

While there was a substantial body of literature on the design and creation of Web pages, the literature tended to concentrate on the aesthetic aspects and the role of the Webmaster rather than on the content (or the representation of content in bibliographical terms) or access. The literature search for this study focused on the content representation and access issues related to that content.

In their study on information-seeking behaviors, Blaise Cronin and Carol Hert (1995) described the scholarly foraging of the Net and showed how the plethora, plurality, and potential instability of resources on Web were a problem for effective searching.

Although they covered a limited set of information clues, Marsha Tate and Jan Alexander (1996) provided an evaluation checklist for various categories of Web pages: advocacy, business/marketing, informational, news, and personal. Their criteria included accuracy, authority, objectivity, currency, and coverage. They provided useful examples of poor Web pages and good Web pages based on these criteria.

According to a survey on Web home page designs for education libraries, Mark Stover and Steven Zink (1996) found very few pages with good designs. They identified some of the sketchy literature pertaining to Web page design principles but said that guidelines for representing the content remained fragmented. They said that many of the pages did not attempt to include fundamental principles of information organization (p. 15). They analyzed the role of the webweaver to plan, analyze, design, and implement the layout, language, techniques for visual communication and targeting the potential audience. Stover et al identified the elements of home pages as the descriptive title, a header that names the organization, the purpose, link choices, and contact information. They noted the importance of 
the date, the authorship, and formats based on the Yale guide which focuses on the function and purpose of the Web page (p. 19). However, the article did not apply the suggestions to the document representation itself. Sowards (1997) updated the information on the evaluation of Web sites by concentrating on the user's perspective to assess identification, authority, layout, design, links and content.

Ding and Marchionini (1996) compared three popular search services: InfoSeek, Lycos, and OpenText Index and stated that none of the engines provided an acceptable precision rate. They also identified the fact that the searches could not be delimited by genres, such as academic articles, newsgroups, or ads. They concluded that users need to be able to select the type of information they seek through efficient classification and filtering mechanisms.

Categorizing the elements of a Web document was addressed through various methods. In her report, Hockey (1996) traced the evolution of the Web publishing codes of Hypertext Markup Language (HTML) and Standard Generalized Markup Language (SGML), and showed how the Text Encoding Initiative (TEI) standards focused on the way in which the content of the information of a Web page is presented and displayed. In addition, the TEI standards attempted to provide a method of "self-cataloguing" to assist in the more organized presentation of a document and its retrieval. However, Hockey pointed out the limitations off TEI in its categorization and classification of the document as a whole. In the TEI system, genre headings referred only to literary genres, such as poetry or drama, and did not to the wide range of electronic genres on the Web, such as directories, journals, conference proceedings, listservs, and the like. She stated that the description of a document using TEI standards fell short of the kind of bibliographic description associated with Library cataloguing, such as MARC codes and AACR2 rules. These library codes identify fields of information and formats of works to characterize the document and to enable the document to be indexed appropriately.

Clifford Lynch (1997) listed the types of resources in the Web's "chaotic repository" of books, papers, raw scientific data, menus, meeting minutes, advertisements, video, audio recordings, and transcripts of interactive conversations. He said that because the Web lacked standard identifiers, robot programs could not extract the routine infonnation such as author, date, length and subject matter (known as metadata). Lynch suggested a solution that would attach the categories of metadata to a Web page for retrieval by a Web crawler (p. 5).

Metadata were defined by the Dublin Core Metadata and Warwick Frameworks and were simpler elements than those in traditional library cataloguing (Weibel, 1997). They included: title, author. subject or keywords, description, publisher, other contributors, date, resource type, format, resource identifier, source and language.

In a recent article, Lynch (1998) reviewed the role of identifiers to authenticate documents, reference other works, and activate search strategies. He identified International Standard Book Numbers (ISBNs), Unifonn Resource Locators (URLs), and Serial Item and Contributor Identifiers (SICIs) as examples of useful labels.

\section{Research Design}

The researcher selected three topics to search on the Web as case studies for this report. The intent was to select topics broad enough to retrieve a substantial but manageable number of hits for each search. The topics selected were the following keyword phrases: 
1. Custom publishing or custom textbooks

2. Distance education in Canada

3. Tactile graphics or braille graphics

The cases represented a snapshot in time. This study is based on the cases available during the September to October 1996 period, when the initial search for this study was completed.

The study population of 600 cases was confined to the top fifty hits for each of the three search topics and four search engines. A random sample of 260 cases was selected from these hits. The random cases were analyzed for information clues according to a set of textual definitions, coded, and entered in a spreadsheet for data analysis.

\section{Findings}

The findings are grouped into two general categories. These include (1): information clues derived from the various fields of information; and (2) the summary field analyzed for information clues.

\section{Information Clues}

An aggregated count of the major information fields in the document representations was produced to determine the overall presence of information clues. The information clues included authors, titles, organizations. genres, language, country, and elements of print works such as chapters and journal volume numbers. The clues were analyzed in relation to the variables: search engines, search topics and rankings. Overall, 1,674 clues were discovered out of a maximum number of 3,120 possibilities, or fifty-four percent of the total potential cases.

Arranged by search topic, there was a wide disparity between the number of clues for each topic. "Custom publishing" showed substantially more clues than either "distance education" or "tactile graphics", which had the least.

The fields of information were analyzed for the number of information clues in each field. The results are shown in Table 1. In a large number of cases, there was a limited number of information clues. For example, the title field displayed few clues to the name or author of a document. Similarly, the summary field did not often show identifiers for organizational or personal responsibility. The summary field was not even very helpful in denoting geographical clues to the country of origin. Of the major variables for which information could potentially be available in the title, URL, and summary document fields in this study, six percent exhibited no information clues.

\section{Summary Field}

Because the summary field mirrors the first few lines of the Web site and is the major paragraph of information presented in the hit list, it represents the best reflection of the Web site itself. The summary field provided the highest number of clues of all the possible fields for the identification of genre. Authorship is a useful clue to assist in selecting the documents a reader wishes to pursue. Although personal authorship was rarely revealed in the summary field, over half the cases in the summary field showed organizational responsibility for the document. 
Table I: Cases with Information Fields that Reveal No Information Clues

\begin{tabular}{|l|c|}
\hline INFORMATION FIELDS & NO CLUES* \\
\hline Title Field. Name Clues & 158 \\
Title Field Clues Other Than Name & 86 \\
Title Field Genre & 195 \\
URL Field Organization & 59 \\
URL Field Language & 0 \\
URL Field: Country & 145 \\
URL Field Genre & 205 \\
Summary Field Organization & 124 \\
Summary Field Author & 204 \\
Summary Field Country & 201 \\
Summary Field Language & 1 \\
Summary Field Genre & 68 \\
TOTAL NO CLUES (out of a possible 3,120 clues) & 1446 \\
*n=260 for each field & \\
\hline
\end{tabular}

Organizations included companies, educational institutions, government agencies, and community groups. Companies represented a little more than double the number of clues on organizations. Educational institutions were revealed in almost a third of the cases.

Most of the recognizable electronic genres in the summary field were ads, followed by electronic texts, articles, directories, indexes, listservs and discussion lists. As might be expected, each of the three topics had its predominant type of document or format. A commercial topic such as "custom publishing" listed a large number of ads. "Tactile graphics," an emerging research topic, showed the largest number of articles or research reports. "Distance education" sites were related more to the institution in which the mode of education was delivered and, understandably, had more indexes, directories and courses listed.

Overall, the topic of "custom publishing" indicated the highest number of organizational clues while "tactile graphics" revealed the lowest number of organizational clues in the summary field. As might be expected. the number of organizational clues for business companies was far greater for the topic of "custom publishing" than for either "distance education" and "tactile graphics." Educational institutions accounted for eighteen of the clues for distance education. The results are shown in Figure 2.

There were very few non-organizational clues identified in the summary field. Non-organizational clues included personal names, events, journals or other words not related to a corporate name. Seventy-eight percent of the cases showed no non-organizational identification. Very few cases revealed personal names with credentials. Therefore, there was little to be gleaned from the summary on the authorship of a document. 


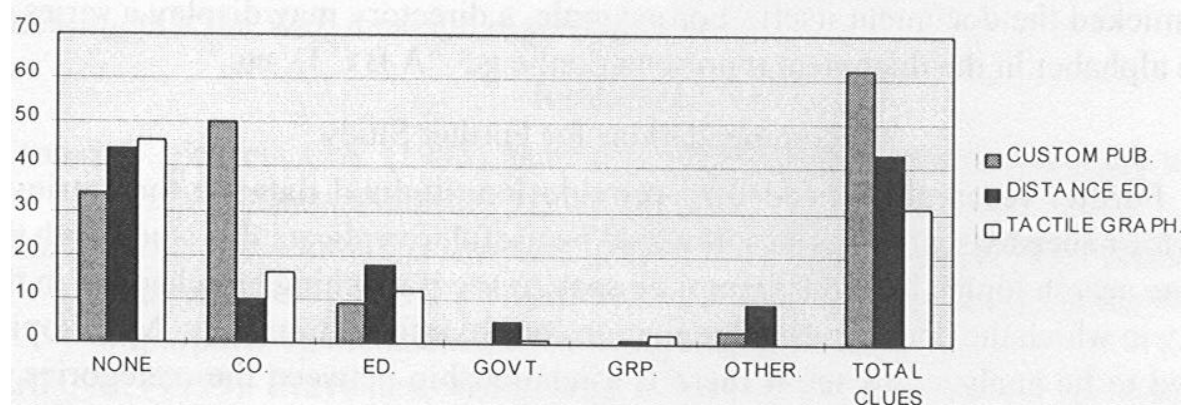

Figure 2: Search Topic and Organization in Summary Field

\section{Discussion of Findings}

A major outcome of the study was the relatively low number of information clues (just over $50 \%$ ). The low incidence of information clues to organization, authorship, and even relevant topics places a large burden on searchers to weed out, filter and sort information before they link to the actual documents for further examination. When there are no information clues, the searcher has two choices: to ignore the entry and move onto the next one, or to link to the full document by clicking on the link to see if it reveals more information. This low level of clues has significance for training in Web searching and for training in Web design.

In this study, the title field was not very productive in revealing useful clues to the document. Personal names, organizational names, and other non-name identifiers were not very plentiful. In many cases, the title field did not deliver clues to the type of document either. The summary field was the most useful part of the document representation for identifying the electronic genre and the organizational name. However, personal authorship was rarely identified. Therefore, these fields of information need to be improved to reveal more useful information about the document itself. The Web designer should place important words at the beginning of the Web page to increase the number of information clues. The lack of authentication is problematic for the searcher because the searcher must take the time to click to the document itself to determine the authenticity of the Web site instead ofdetermining the validity from the document representation. If the words are not in the document itself, they cannot be found through search engines.

The electronic genres were found most often in the summary field. However, it is necessary to know how information is structured to identify the type of clues available for electronic genres. Specific words in the document representation in 
the summary field revealed the format of some books such as a bibliography, a biography, a hypertext link, a report, a discussion list, a journal, or a part of a book. Other clues were found through the way in which the document representation mimicked the document itself. For example, a directory may display a series of the alphabet in the document representation; e.g., "A B C D, etc."

\section{Recommendations for Further Study}

Further research is needed to provide longitudinal data on the retrieval performance by search engines. It would be useful to replicate this study with the same search topics for a different time span to see if anything has changed in the way in which the document representations reveal information clues. More topics need to be analyzed to see if there is a relationship between the categories of topics, whether they are commercial, academic, or a hybrid, and the number of information clues. The demographics of Web authors might also be analyzed to see what factors influenced their design of the Web sites in terms of information clues.

\section{Recommendations for Design Improvements FOR WEB authors}

Authors who wish to have their sites discovered need to include more information clues by designing their pages for easier retrieval and more meaningful selection. A template should be created for Web authors to assist them in the selfidentification of the information clues on organization, country, language, content, authorship and genre. It would be useful for the author of Web pages to provide a geographical description of the location of the information either from the point of view of the originator or the point of view of the topic and its relevance to a geographical place.

The size of the title field in Web displays is currently quite limited. A template could assist authors to maximize the limited space by including the required core elements of the topic, authorship, and genre characteristics.

Significant progress has been made to identify the elements which make up a core metadata set as a new bibliographic standard for improved access to Web pages. As Stuart Weibel (1996) recommends. the metadata convention should be embedded in the HTML coding.

\section{Conclusion}

Although there are many advocates for better organization of the Web to improve access, the changes will likely not be implemented in the current Web architecture for some time. As a result, searchers are still limited to the access provided by search engines that use robots to collect words from the documents for retrieval purposes. Robots, and search engines relying on robots. are not able to pick the clues and list them in the document representation unless the authors include these searchable keywords in relevant fields. Because the summary field is a literal transcription of the text on the Web site page. authors of Web pages should construct the information on the page for more effective retrieval. This 
entails including important words at the top of the site: the topic, authorship, organizational responsibility. country, language, and genre. These elements of information clues will help the searcher (or surfer) find documents more efficiently, ensuring that the Web message is getting through.

\section{References}

Cronin, B.. \& Hert, C.A. (1995). Scholarly foraging and network discovery tools Journal of Documentation, 51(4), 388-403.

Dublin Core Metadata Element Set: Reference Description. (1997). [online]. January 15. 1997 [cited 17 April 1997]. Available from: World Wide Web: <http://purl.org/metadata/dublin_core elements/title>.

Ertel, M. (1995). Brave new world: what a working librarian should know about living on the internet. Searcher: The Magazine for Database Professionals 3, 28-30.

Hockey, S. (1996). Describing electronic texts: the text encoding initiative and SGML [online]. [cited 30 July 1996]. Available from World Wide Web: <URL:http://www.loc.gov/catdir/semidigdocs/hockey.html>.

Lancaster, F.W., \& Warner, A.J. (1993). Information retrieval today, rev. retitled and expanded ed. Arlington, VA: Information Resources Press.

Lynch, C. (1998). Identifiers and their role in networked information applications. Feliciter 44(2), 3 1-35

(1997). Searching the internet Scientific American [online]. March 1997 [cited 3 April 1997]. Available from World Wide Web: <URL:http:// www.sciam.com/0397issue/O397lynch.html>

Ormondroyd. M. E., \& Cosgrave, T. (1997). How to critically analyze information sources [online]. [cited 9 January 1997]. Available from World Wide Web: <URL:http://www.library.cornell.edu/okuref/research/skill26.html>.

Stover, M. \& Zink, S.D. (1996). World wide web home page design: patterns and anomalies of higher education library home pages. RSR: Reference Services Review, 24(3). 7-20.

Tate, M., \& Alexander, J. (1996). Teaching critical evaluation skills for World Wide Web Resources. Computers in Libraries, 16(10), 49-55.

Tomaiuolo, N.G., \& Packer, J.G. (1996). An analysis of internet search engines: assessment of over 200 search queries. Computers in Libraries, I6(6), 58-62.

Wei Ding, W., \& Marchionini, G. (1996). A comparative study of web search service performance. In ASIS '96: Proceedings of the 59th ASIS annual meeting, Baltimore, Maryland, October 21-24, 1996. Medford, N.J.: Information Today.

Weibel, S. (1996). A proposed convention for embedding rnetadata in HTML [online]. June 2, 1996 [cited I7 April 1997]. Available from World Wide Web: <URL:http://www.ocIc.org/-weibel/html-meta.html>.

Westera, G. (1997). Robot-driven search engine evaluation overview [online]. October 1996 [cited 9 January 1997]. Available from World Wide Web: 
<URL:http://www.curtin.edu.../personal/senginestudy/>.

Younger, J.A. (1997). Resources description in the digital age. Library Trends, 45(3), 462-481.

Zorn, M.J., Emanoil, M., \& Marshall, L. (1996). Advanced web searching: tricks of the trade. Online, 20(3), 14- 16.

\section{$\overline{A U T H O R}$}

Mary Anne Epp is Director of Contract Administration, Library Services at Langara College, 100 W. 49th Avenue, Vancouver, B.C. V5Y 2Z6. E-mail maepp@langara.bc.ca 


\section{Book Review}

\section{Diane .Janes, Editor}

Using Technology in the Classroom by D. LaMont Johnson, Cleborne D. Maddux, and Leping Liu (Ed). New York: Haworth Press, 1997. ISBN 078900311-2 (hardback: \$49.95); ISBN 0-7890-0352-X (paperback: \$24.95; outside US/Canada/Mexico \$30). Co-published as Computers in the Schools. vol. 13, no. 1/2, 1997.

\section{Reviewed by Mary Anne Epp}

This collection of short papers portrays a wide range of approaches to the implementation of technology in the elementary, high school, college and university classroom. The articles provide glimpses of practical applications in all areas of the classroom environment. The reports are written by university educators (most are professors) in many different colleges and universities in the United States. There are also three reports from other countries: Spain, the United Kingdom and Canada. Most of the articles have a research relationship and all the articles cite references to research and related literature.

Most of the writers are uncritical proponents of integration of technology into the classroom. Only Patricia Pokay and Carla Tayeh evaluate the experience of integration with some critical analysis. In their article, "Integrating Technology in a Geometry Classroom." Pokay and Tayeh point out some of the difficulties the students had in their initial introduction to the use of the technology. The difficulties retarded the focus on content in the early stages of the integrative program. John A. Swartz generates a more philosophical approach in his provocative historical piece on media literacy, "Is the RCA Dog Real?"

The majority of the articles describe technology applications in subject disciplines, such as mathematics, geometry, algebra. sciences, visual arts, language learning, writing, social studies (geography), and teacher education. Several articles discuss thematic issues. such as classroom management, behaviour modification (for children with attention deficit disorders), collaborative partnerships across jurisdictions, diversity, special needs (indirectly). student evaluation of instruction, and media literacy.

Most of the studies are descriptions of case studies of projects or programs in the practice of the educational institution. However, there is one model for computer integration by Karen Smith-Grafto and Marcy A. Blackburn in "The Computer as 
a Scientific Tool: Integrating Spreadsheets into the Elementary Science Curriculum." The article, "The Dance of Change: Integrating Technology in Classrooms," by Karin M. Wiburg is perhaps the most extensive research paper in the compilation. Wiburg describes a collaborative university/public school collaborative search project with specific research questions addressing the nature of collaboration, use of personal experience by students, effectiveness of opportunities of students to use network-based materials, professional development effectiveness, and dissemination of information to pre-service and in-service teachers. Ms. Wiburg concludes that the investment in people and customized applications are essential to effective integration and will not replace the 'turnkey' approach to integrated learning systems.

Technological tools described in the articles cover a wide range of applications including generic spreadsheets, CD ROM, multimedia authoring systems, databases, the Internet, and specifically the World Wide Web. Specific programs, such as VISPRO: Grafies are included in Xavier Bornas' article from Spain ('Preventing Impulsivity in the Classroom: How Computers Can Help Teachers.') Several specific Web sites, such as the JASON Project, Kid projects, and GlobaLearn on the World Wide Web are mentioned in the Stephen Lafer article, "Audience, Elegance, and Learning via the Internet." Lafer focuses on the development of a 'real audience' for writing improvement.

The articles themselves are generally well selected by the editors to provide a wide range of ideas and specific practical applications for teaching and teacher education. However, the introduction does not provide a cohesive overview of the content. The reader must search the introduction to each article separately to determine its content and usefulness. The introductory article to the collection by D. LaMont Johnson stands alone as an editorial to the topic of technology integration. While many of the articles are generic and applicable to education generally, the Johnson's article shows a very biased American slant, belying the more international relevance of the reports in the compilation. A summary of the articles at the outset would have been useful to tie the pieces together. The book does not attempt to cover the topic comprehensively, but is rather a selective sampling of some of the approaches specific educators have tried. Articles on information skill development and integration of students with disabilities would have provided enhanced coverage. The need for developing related information competencies are absent in all but one article by Louise Hay. She hints at some strategies for developing information skills in her report. "Tailor-Made Instructional Materials Using Computer Multimedia Technology." As with many books on educational technology and specifically, the use of the Web, most of the writers in this compilation seem to take it for granted that students have the information skills necessary to understand the data they are receiving through the Web. Also missing is a treatment of integrating students with disabilities into the classroom through adaptive technology. The Index is very selective and spotty; for example, 
it does not pick up the reference to the Alberta (or Canadian) projects discussed by Peter Wright in the only Canadian article in the bunch.

Structurally, the compilation is somewhat misleading. After the introduction, there are two sections named Research and General. Only the Cleborne Maddux article on "The World Wide Web and School Culture" (and primarily an opinion piece based on selected statistics) is located in the Research Section. Wiburg's "The Dance of Change", perhaps the most detailed research article in the collection, is provided in the General Section.

Generally, this is a very good book for practitioners beginning to integrate technology in their classrooms, if they do not have access to other magazines such as Tech Trends. Computers in the Schools, etc. The compilation is also useful for researchers looking for prototypes of research projects on integration and wishing to build on previous research. Educators who are looking for applications useful for distributed learning may find the projects useful for adaptation into the online world, although none of the articles specifically address the distributed learnmg environment.

\section{$\overline{R E V I E W E R}$}

Mary Anne Epp is Director of Contract Administration, Library Services at Langara College. 100 W. 49th Avenue, Vancouver, B.C. V5Y 226. E-mail maepp@langara.bc.ca 
56 CJEC SPRING 1997 


\title{
Microware Review
}

\author{
L.F. (Len) Proctor, Editor
}

The Digital Field Trip to the Wetlands by Digital Frog International, Trillium Place, RR\#2, Puslinch, Ontario, NOB 2J0

\section{Reviewed by Dell Franklin}

The Digital Field Trip to the Wetlands is the first in a series of "field trips" produced by Digital Frog International. The virtual tour of a bog environment is the flagship portion of the program with four other major topics that would be of interest to a young ecology students.

The package contains the program on compact disk, an instructor's guide and a student's guide. The instructor's guide is a brief introduction to the values and uses of the package followed by a copy of the student's guide with answers. The learning ob.jectives are clearly delineated in the instructor's guide and the student 's guide. The student's guide also contains a brief introduction to the workbook and a series of questions providing guidance on how to use the CD. This section is followed by a series of lists, rules and questions (with answers) which are generic enough to be used on any field trip to a wetland area but which can also be used to explore the CD. Lastly, a set of study questions are provided to reinforce the material found on the CD.

This package has been designed for a grade IO age group. The ecological approach is appropriate for study units in chemistry, biology, geography and environmental science. As suggested by the

teacher's manual, this program could even be used as a supplement to a language arts program because the text in the glossary is reinforced by a digital sound pronunciation of the word.

Unfortunately the attempts at humor in the student's guide border on the sarcastic. For example. the equipment list for real field trips contains the phrase: "Knapsack (unless you have more than two hands)" (p.2). This style detracts from the more meaningful examples regarding mosquito repellent, floatation devices and pens. 


\section{The Study of a Bog}

This section of the program contains three major foci: Formation and Succession, The Bog Food Web, and Adaptations in a Bog. Each of these are separate and the learner is free to choose the order and pace to proceed.

The Formation and Succession of Bogs is a tutorial that has two animated segments describing glacial formation and formation by beaver ponds. These contain higher order concepts involving geological time lines and are very clear and concise.

The immense span of time is functionally handled by the animation format and is reinforced by a moving time line along the bottom of the screen. These animations will play continuously or increased learner control takes place with the option of sliding the time line. A negative feature of the animations is the duplicity which takes place as the text is read to the learner. An increased form of learner control could be where the learner hears a different content line and/or has the option to turn the sound off.

The Bog Food Web is definitely the largest content area of the section The Study of a Bog and is also the most interactive of the three. While the five tutorials: Food Chains, Food Web Energy, Producers, Consumers and are all linear with text reinforced by graphics of each concept, the species examples used are hyperlinked to the organism screens. The organism screens are similarly available from various other sections of the program and provide the learner with a wide variety of examples of species found within wetland areas. The Bog Food Web section also contains the Bog Food Web Game where the ecological concept of food webs and food chains are reinforced by linking consumers with food sources. In this screen, the learner may also hyperlink to the organism screens of each species in the game. Only correct links are allowed and the user can check the accuracy of their web at any time, receiving a number of correct links out of a total number of links. Furthermore, the score screen allows the user to view the total correct links highlighted, the links they had correct as well as the links by species.

In Adaptations in a Bog, there are two main sections. The section Adaptations in Animals has interesting examples of bird species and their adaptations to the winter environment. The learner interacts here by having to choose which birds do not migrate and select, on a different screen, where their food source may be located. This is an effective, however there an a large portion of adaptations among different species which are ignored, for example amphibian breathing in water environments. While it would be unreasonable to expect examples of all species in a wetland, the instructional design should have allowed for animals and insects to be shown rather than birds alone. The second section, Adaptations in Plants, also has interesting examples of interaction however there are few previous cues which would help a learner select how bog plants assimilate nitrogen from their environment. Again, textual feedback is used for incorrect answers with a game format used on a different screen showing the actual method the plants have adapted. 
Once again, the two specific types of plants used are an inadequate sample of the wide range of plant adaptations within a bog environment.

\section{Wetland Types}

This section has a variation on the graphical interface used. It begins with a split screen with four examples of wetland types shown and a description box in the middle. In the box is the options of playing the Wetland Types Game or viewing Other Classification Names for wetlands. By clicking on a photograph of a type of wetlands, the user is shown a diagram and photographic example for each type. This is the extent of the examples except for the peat lands example, which the designers break up into fens and bogs. This choice was content based as these two types are shown to have distinct similarities with an interactive comparison utilized. This interaction takes place via a split screen of the two types and if the learner clicks on an element in either photograph the program provides either a text or graph explaining the differences.

In the game the learner is shown photographs of various wetlands and then clicks on the multiple choice area. This area uses the metaphor of aremote control unit (RCU) and on this unit feedback is shown by several methods. A continuous score is shown on the RCU and if the learner is correct on the first try a higher score is given than on subsequent tries. Four tries are allowed with decreasing scores for each attempt and hints for each attempt are supplied.

\section{Mechanisms of a Wetland}

This portion of the program has the least amount of interaction for the learner. The more abstract concepts of Nutrient Cycles, Groundwater, Productivity, Wetlands, and Erosion and flooding are explained through text and, for the last three. some animation which the learner controls through buttons. The interface is consistent with the rest of the package.

\section{Our Endangered Wetlands}

This segment of the program web contains the sections Migration, Wetlands as Habitat, Conservation, and Pollution. The navigation scheme of the majority of the program is similar here with the initial screen showing the jigsaw sections. The migration focuses on birds and the initial screen is a text introduction with the example species graphically listed below. By clicking on the bird the learner, sees a set of folders with pictures, maps, and possible movies of that species. On that screen is also hyperlinked text describing habitat, behaviour, range, food source, and migration. Also listed are the size and Latin name, the latter having a pop-up showing the taxonomy of that species.

The Wetlands as Habitat has a couple of unique features. While it shares the same appearance as Conservation and Pollution, it's text is first person with the species addressing the learner. The learner also has the option to hear the species read the text to them in a variety of voices, both male and female. The content of 
strategies while other areas leave the impression that production deadlines may have caused these areas to be compiled in a hurry.

Not withstanding these drawbacks this software package provides a unique learning experience for young people concerned with the environment. Many people do not have the economic or geographic ability to visit wetland areas and The Digital Field Trip to The Wetlands uses the latest technologies of computer based instruction to give a very realistic account of the wetlands experience.

\section{Recommended System Requirements}

The hardware/software requirements are clearly labelled on the materials accompanying the $\mathrm{CD}$. Basic requirements are:

PC version- a $386 \mathrm{X} / 25$ or better, $8 \mathrm{MB}$ RAM, CD-ROM drive, Windows 3.1, VGA/SVGA displaying - 640x480 256 colours, with a sound card recommended.

Macintosh - LCII or better (16MHz 68030 machine), 5 MB RAM, CDROM drive, System 7, screen capable of displaying 640x480 256 colours.

\section{$\overline{R E V I E W E R}$}

Dell Franklin is a graduate student in the Department of Curriculum Studies (Education Communications) in the College of Education at the University of Saskatchewan, Saskatoon, SK. 


\section{Information for Authors}

CJEC welcomes papers on all aspects of educational technology and communication. Topics include, but are not limited to: media and computer applications in education, learning resource centres, communication and instruction theory, instructional design, simulation, gaming and other aspects of the use of technology in the learning process. These may take the form of reviews of literature, descriptions of approaches or procedures, descriptions of new applications, theoretical discussions and reports of research. Manuscripts may be submitted either in English or in French.

\section{Manuscript Categories}

Manuscripts may fall into one of two classes: General, dealing with a topic or issue at a general level (although reference to specific instances or examples may be included), and Profiles, dealing with or describing only a specific instance of an approach, technique, program, project, etc. A Profile may be thought of as a descriptive case study. Most manuscripts dealing with a topic in general should include reference to supportive literature, while manuscripts submitted to the Profile category may or may not make such reference. The Editor reserves the right to change the designation of a manuscript or to make a designation, if none has been made previously by the author. Authors interested in determining the suitability of materials should consult past issues of CJEC or contact the Editor. Al! manuscripts received by the Editor (either general or profile) will be judged for suitability, contribution, accuracy, etc. by a panel of anonymous reviewers designated at the time of submission. Normally, the review process requires about eight weeks. There are no deadlines for the submission of manuscripts.

\section{Manuscript Preparation}

Manuscripts should be printed on $8 \%$ x 11 inch ordinary white paper. All materials must be double-spaced, including quotations and references, include a title page on which appears the title of the manuscript, the full name of the author(s) along with position and , institutional affiliation, mailing address, e-mail address, and telephone number of the lcontact author. An abstract of 75-150 words should be placed on a separate sheet folllowing the title page. While the title should appear at the top of the first manuscript page, no reference to the author(s) should appear there or any other place in the manuscript. Elements of style, including headings, tables, figures and references should be prepared according to the Publication Manual of the American Psychological Association 4thEdition, 1994. Figures must be camera ready if not in electronic form.

\section{Submission of Manuscripts}

Send four copies of the manuscript to the Editor along with a letter stating that the manuscript is original material that has not been published and is not currently being considered for publication elsewhere. If the manuscript contains copyright materials, the author should note this in the cover letter and indicate when letters of permission will be forwarded to the Editor. Manuscripts and editorial correspondence should be sent to: David A. Mappin, Canadian Journal of Educational Communication, Faculty of Alberta Edmonton, Alberta, T6G 2G.5. E-mail: David.Mappin@ualberta.ca 